\title{
Overview and Computational Approach for Studying the Physicochemical Characterization of High-Boiling-Point Petroleum Fractions $\left(350^{\circ} \mathrm{C}^{+}\right)$
}

\author{
L. Plazas Tovar ${ }^{1 *}$, M.R. Wolf Maciel' ${ }^{1}$, R. Maciel Filho², C.B. Batistella', O.J. Celis Ariza² \\ and L.C. Medina ${ }^{3}$ \\ 1 Separation Process Development Laboratory (LDPS), School of Chemical Engineering, State University of Campinas-UNICAMP, \\ Zipcode 13083-852, Campinas - Brazil \\ 2 Optimization, Project and Advanced Control Laboratory (LOPCA), School of Chemical Engineering, State University of Campinas-UNICAMP, \\ Zipcode 13083-852, Campinas - Brazil \\ 3 Centro de Pesquisas e Desenvolvimento da Petrobrás (CENPES/Petrobrás), Rio de Janeiro - Brazil \\ e-mail: Iplazast@feq.unicamp.br -wolf@feq.unicamp.br - maciel@feq.unicamp.br - doutorbatistella@uol.com.br \\ oscarcel26@gmail.com - Imedina@petrobras.com.br \\ * Corresponding author
}

\begin{abstract}
Résumé - Approche informatique pour l'étude des propriétés physico-chimiques de fraction pétrolière lourde $\left(350{ }^{\circ} \mathbf{C}^{+}\right)$- Le traitement et la valorisation des fractions pétrolières lourdes nécessitent une étude très détaillée dans la mesure où le pétrole contient un très grand nombre de composants différents (paraffines, oléfines, naphtènes, arômes). Afin de caractériser les fractions, il est indispensable de déterminer les propriétés thermodynamiques et thermophysiques des différents éléments.

Ce travail présente une approche informatique qui peut être utilisée pour l'évaluation et l'estimation des propriétés des fractions pétrolières lourdes. La fraction pétrolière est divisée en un nombre arbitraire de pseudo-composants. Des cas d'étude ont été illustrés pour trois résidus lourds, issus d'un nombre égal de pétroles bruts "X, Y et Z". La procédure nécessite en entrée le point d'ébullition, la courbe de distillation et la densité volumique de l'ensemble de la fraction lourde. Les méthodes existantes, issues des corrélations disponibles dans la littérature et des standards industriels, ont été principalement employées pour estimer les propriétés basiques (le point d'ébullition normal, la densité et facteur de caractérisation de Watson), les propriétés thermodynamiques (masse molaire et propriétés critiques) et les propriétés thermophysiques (viscosité cinématique, conductivité thermique, capacité calorifique et pression de vapeur saturante).

La méthode développée s'est montrée être un outil efficace pour calculer les propriétés des fractions pétrolières avec précision, quand les informations de départ sont disponibles. La prédiction des propriétés montre de bonnes correspondances avec les résultats obtenus auparavant dans les laboratoires de recherche LDPS/LOPCA de l'UNICAMP, avec un écart global absolu inférieur à $10 \%$.
\end{abstract}

\footnotetext{
Abstract - Overview and Computational Approach for Studying the Physicochemical Characterization of High-Boiling-Point Petroleum Fractions $\left(350^{\circ} \mathrm{C}^{+}\right)$- The processing and upgrading of high-boilingpoint petroleum fractions, containing a large number of components from different groups (paraffins, olefins, naphthenes, aromatics) require an in-depth evaluation. In order to characterize them, their thermodynamic and thermophysical properties must be determined.
} 
This work presents a computational approach based on the breakdown of the petroleum fraction into pseudocomponents defined by a trial-and-error exercise in which the mass- and molar-balance errors were minimized. Cases studies are illustrated to three heavy residues $400^{\circ} C^{+}$from " $W, Y$ and $Z$ " crude oil. This procedure requires the boiling point distillation curve and the density of the whole fraction as the input bulk properties. The methods proposed according to available correlations in the literature and standard industrial methods were mainly used to estimate properties that include the basic properties (normal boiling point, density and Watson factor characterization), the thermodynamic properties (molar mass and critical properties) and the thermophysical and transport properties (kinematic viscosity, thermal conductivity, specific heat capacity and vapor pressure).

The methodology developed has shown to be a useful tool for calculating a remarkably broad range of physicochemical properties of high-boiling-point petroleum fractions with good accuracy when the bulk properties are available, since computational approach gave an overall absolute deviation lower than $10 \%$ when compared with the experimental results obtained in the research laboratories LDPS/LOPCA/UNICAMP.

\section{NOTATION}

$C_{p} \quad$ Specific heat capacity of whole fraction $\left(\mathrm{J} \cdot \mathrm{kg}^{-1} \cdot \mathrm{K}^{-1}\right)$

$C A B P$

$E_{\text {mass }}$

$E_{\text {mol }}$

$K_{U O P}$

$K_{w}$

$M$

$M A B P$

$M e A B P$

$M e A B P^{*}$

Cube of the Average Boiling Point (K)

Material balance error (-)

Molar balance error (-)

Universal Oil Products Company characterization factor (-)

Watson characterization factor (-)

Molar mass $\left(\mathrm{kg} \cdot \mathrm{kmol}^{-1}\right)$

Molar Average Boiling Point (K)

Mean Average Boiling Point (K)

Point $(\mathrm{K})$

$M_{\text {NPSE }}$

$n$

$P_{c}$

$P_{c_{\text {NPSE }}}$

$P_{\text {vap }}$

$S G$

$T$

$T_{b}$

$T_{b i}$

$T_{b_{r}}$

$T_{c}$

$T_{c_{N P S E}}$

$V A B P$

$V_{c}$

$V_{c_{\text {NPSE }}}$

$W A B P$

$x_{m i}$

$x_{v i}$

$x_{w i}$

Molar mass of pseudocomponent $\left(\mathrm{kg} \cdot \mathrm{kmol}^{-1}\right)$

Number of pseudocomponents (-)

Critical pressure $(\mathrm{Pa})$

Pseudocritical pressure $(\mathrm{Pa})$

Vapor pressure of whole fraction $(\mathrm{Pa})$

Specific Gravity (-)

Temperature (K)

Boiling point $(\mathrm{K})$

Normal boiling point $(\mathrm{K})$

Reduced boiling point $T_{b_{r}}=T_{b} / T_{c}(-)$

Critical temperature (K)

Pseudocritical temperature (K)

Volumetric Average Boiling Point (K)

Critical volume $\left(\mathrm{m}^{3} \cdot \mathrm{mol}^{-1}\right)$

Pseudocritical volume $\left(\mathrm{m}^{3} \cdot \mathrm{mol}^{-1}\right)$

Weight Average Boiling Point $(\mathrm{K})$

Molar fraction of pseudocomponent (-)

Volume fraction of pseudocomponent (-)

Weight fraction of pseudocomponent (-)

\section{Greek letters}

$\lambda \quad$ Thermal conductivity of whole fraction $\left(\mathrm{W} \cdot \mathrm{m}^{-1} \cdot \mathrm{K}^{-1}\right)$

$\mu \quad$ Dynamic viscosity of whole fraction $(\mathrm{Pa} \cdot \mathrm{s})$

$v \quad$ Kinematic viscosity of whole fraction $\left(\mathrm{m}^{2} \cdot \mathrm{s}^{-1}\right)$

$\rho \quad$ Density of whole fraction $\left(\mathrm{kg} \cdot \mathrm{m}^{-3}\right)$

$\rho_{i}, \rho_{\text {NPSE }}$ Density of pseudocomponent $i\left(\mathrm{~kg} \cdot \mathrm{m}^{-3}\right)$

$\rho_{\text {water }} \quad$ Density of water (at $\left.288.15 \mathrm{~K}\right)\left(\mathrm{kg} \cdot \mathrm{m}^{-3}\right)$

$\sigma \quad$ Shear rate $\left(\mathrm{s}^{-1}\right)$

$\tau \quad$ Yield stress $(\mathrm{Pa})$

$\omega_{a c} \quad$ Acentric factor (-)

$\omega_{a c_{N P S E}}$ Acentric factor of pseudocomponent (-)

\section{Subscript}

$i \quad$ Pseudocomponent $i$

NPSE Pseudocomponent

\section{Superscript}

$L_{s} \quad$ Left side

$R_{s} \quad$ Right side

* $\quad$ Starting value

\section{Acronyms}

ASTM American Society for Testing and Materials

ATR Residue from conventional atmospheric distillation (ASTM D 2892, 2005)

BP Boiling Point distillation data

CENPES Petrobras Research and Development Center

NDATA Number of input data for the BP data

NDGER Degree of Lagrange's interpolation polynomial

NITER Maximum number of iterations

UOP Universal Oil Products Company

TBP True Boiling Point

W, Y, Z Dummy names for ATR fractions 


\section{INTRODUCTION}

Investment in technology in the petroleum industry is increasing and this is essential both to enable the use of available oil reserves worldwide, and to refine petroleum with different physical and chemical characteristics. This growth has led to the establishment of numerous companies in this sector and the development of research and engineering projects with technological bias, in order to ensure improvement in petroleum yield and quality, increasing competitiveness in this sector.

Petroleum fractions are undefined mixtures of hydrocarbon compounds with a limited boiling point range, and their properties depend on their compositions and types of hydrocarbon present in the mixture (aromatics, paraffins, olefins, and naphthenes). Subsequently, in the field of production, refining, processing and upgrading technologies for petroleum fractions, the values of the basic, thermodynamic and thermophysical properties must be available (Merdrignac and Espinat, 2007).

In general, three classes of predictive correlations are published in the open literature:

- one class contains the group contribution method, but it can not be used for mixtures of unknown structure and composition (e.g. high-boiling-point petroleum fractions);

- another approach is via models using basic components (paraffinic hydrocarbons and naphthenic compounds) (Hu and Zhu, 2001; Quann and Jaffe, 1992). In this case, the crude oil, fraction or cut obtained by distillation, is represented by a set of hypothetical components (basic components) of the same molar mass (Riazi, 2004) or even with the same number of carbon atoms (Danesh, 1998);

- the last class comprises a pseudoization approach, where the properties are estimated from their basic properties, such as the boiling point $\left(T_{b}\right)$, Specific Gravity $(S G)$ and Watson factor characterization $\left(K_{w}\right)$ (Daubert and Danner, 1997).

Hence, this work presents an accurate computational approach used for evaluating and estimating the physicochemical properties of three (3) petroleum fractions (highboiling-point petroleum fractions). The petroleum fraction was broken down into pseudocomponents based on the knowledge of their global properties such as the Boiling Point distillation data (BP) of the whole fraction and the Specific Gravity $(S G)$. The methodology adopted in this work was based on the procedure presented by Miquel and Castells (1993, 1994). The aim of the work consisted of two parts:

- the first part consisted of the estimation of the basic properties and the thermodynamic properties (such as molar mass $(M)$, density $(\rho)$ and critical properties (critical temperature $\left(T_{c}\right)$, critical pressure $\left(P_{c}\right)$, critical volume $\left(V_{c}\right)$ and acentric factor $\left.\left(\omega_{a c}\right)\right)$ based on a route for the minimization of the error, depending on the type of correlation set used;
- the second part consisted of the estimation of the thermophysical properties (kinematic viscosity $(v)$, thermal conductivity $(\lambda)$, specific heat capacity $\left(C_{p}\right)$ and vapor pressure $\left.\left(P_{\text {vap }}\right)\right)$.

The characterization procedure was carried out for each whole fraction and for the set of pseudocomponents (NPSE), identifying each physicochemical property with a subscript NPSE. The choice of correlation depends on: a) the use of the specific property or the input data to predict another property; and b) the accuracy and range of applicability of the property. The reliability of the data estimated by the computational approach (pseudoization method) was determined by comparison with the experimental information. Taking into account that the modeling approach is not exact, but approximate, its inaccuracy was evaluated by approximation regarding to experimental data. Results estimated in order to retry the basic properties of the entire fractions were evaluated in terms of the minimization of mass- and molar-balance error. On the other hand, thermophysical and transport properties, in the temperature range between $350 \mathrm{~K}$ and $600 \mathrm{~K}$, were evaluated in terms of Average Absolute Deviation ( $A A D \%$ ) which is define as a relation among the absolute deviation of estimating a quantity divided by its experimental value $\left(y_{i, r e f}\right)$. The absolute deviation is defined as the difference between the observed value $\left(y_{i, r e f}\right)$ and the response predicted by the modeling approach at each operating condition $\left(y_{i, c a l}\right)$ as follows:

$$
A A D \%=(1 / m) \sum_{i=1}^{m} \frac{\left|y_{i, c a l}-y_{i, r e f}\right|}{y_{i, r e f}} \times 100
$$

\section{PSEUDOIZATION METHOD FOR THE CHARACTERIZATION}

The pseudoization approach for petroleum fractions was developed in several research projects, independent of the kind of compound.

Coats (1985) made an important contribution to connected computer simulation by creating a grouping of dummy components. This approach is known as pseudoization, and it aims to reduce the number of elements necessary to represent a fluid, reducing the computational effort. A pseudocomponent was defined primarily by its (pseudo) normal boiling temperature and by some other parameters, specifically the Specific Gravity $(S G)$ and molar mass $(M)$ or kinematic viscosity $(v)$.

Schlijper (1986) developed a method in which a pseudocomponent represented a mixture of components, and thus the thermodynamic behavior of the mixture was determined from the equation-of-state.

Miquel and Castells $(1993,1994)$ presented a computational methodology for predicting the properties of components of a mixture based on the hypothesis of constant Watson's 
characterization factor, $K_{w}$, for all the pseudocomponents of the mixture.

Beer (1994) described a method for the characterization of petroleum fractions and for the breakdown of pseudocomponents. This approach requires an inspection of the ASTM analyses or TBP (True Boiling Point) distillation curves as the input data.

Riazi and Al-Sahhaf (1996) developed a generalized correlation for the properties of several homologous series of hydrocarbons in terms of their molar mass. This approach can be applied to hydrocarbons up to $\mathrm{C}_{50}$.

Eckert and Vaněk (2005) presented a brief description of the pseudoization approach for the characterization of petroleum fractions.

Nichita et al. (2008) proposed an approach for the modeling of wax precipitation from hydrocarbon mixtures. The modeling requires extended compositional data for the high-boiling-point petroleum fractions. The method is based on lumping into pseudocomponents, which reduces the dimensionality of the phase equilibrium calculations without affecting the location of the solid phase transitions.

Satyro and Yarranton (2009) suggested a procedure based on the representation of the mixture of real components that boil within a certain boiling point interval, by hypothetical components that boil at the average normal boiling temperature. This procedure is advantageous, since it is completely general and is not based on a specific thermodynamic model for the mixture.

\section{OVERVIEW OF THE ESTIMATION OF THE PHYSICOCHEMICAL PROPERTIES}

The physicochemical properties are perhaps one of the most important factors in both experimental and theoretical researches, since they are needed to predict the performance of the process, the behavior of the material under the operating conditions and the modeling and the simulation of the industrial processes.

However, important limitations in the use of the methods are present, such as the availability of the input parameters e.g. some critical property of the petroleum fractions and the range of applicability of the methods. Thus, an inadequate estimation of the physicochemical properties of the highboiling-point petroleum fractions may result in low reliability of the prediction of the performance process under study (Riazi, 2004). Hence, specific methods for the estimation of the basic, thermodynamic, thermophysical and transport properties are given in the following sections.

\subsection{Prediction of the Basic Properties}

\subsubsection{Characterization of the Average Boiling Points}

High-boiling-point petroleum fractions, being mixtures of several compounds, present an average boiling point, which is inappropriate from the physical point of view, since volatility is associated with a single boiling point. However, even though it is considered inadequate to define the average boiling point of a mixture, this is the usual practice, because it allows the estimation of the properties of the petroleum fractions and petroleum cuts by standard industrial methods and for a correlation with values cited in the literature. Thus, Watson et al. (1935) proposed methods to calculate the so-called average boiling point of the whole mixture, as presented in Equations (2-6) from Table 1.

\subsubsection{Characterization Factor}

The Watson characterization factor $\left(K_{w}\right)$ or Universal Oil Products Company (UOP) characterization factor $\left(K_{U O P}\right)$ is the ratio of the cube root of the absolute boiling point (of a pure component) or the average normal boiling point for petroleum cuts to the specific gravity. It is used as an approximate index of the paraffinicity of a petroleum cut, thus a high value for this index indicates a high percent of saturated pure components and paraffin components (Gharagheizi and Fazeli, 2008; Watson and Nelson, 1933).

The $K_{w}$ is defined as follows:

$$
\begin{gathered}
K_{w}=K_{U O P}=\frac{\sqrt[3]{1.8 T_{b}}}{S G} \\
S G=\frac{\rho}{\rho_{\text {water }}}
\end{gathered}
$$

where, $T_{b}$ is the normal boiling point; and for whole petroleum fraction is the Mean Average Boiling Point (MeABP) (in Kelvin). Therefore, the $S G$ is the ratio of its density $(\rho)$ to the density of the water $\left(\omega_{\text {water }}\right)$ at $288.15 \mathrm{~K}\left(15.6^{\circ} \mathrm{C}\right.$ or $\left.60^{\circ} \mathrm{F}\right)$.

\subsection{Estimation of the Thermodynamic Properties}

The critical properties $\left(T_{c}, P_{c}, V_{c}\right.$ and $\left.\omega_{a c}\right)$ of unknown mixtures can be estimated as a function of $T_{b}$ and $S G$ (Boozarjoomehry et al., 2005). The critical properties are parameters commonly used by process simulators in the design of unit operations and in the estimation of the thermophysical properties. Several methods have been proposed and some are presented in Equations (9-17) from Table 2. For estimating $M$, the methods available are very similar to those used in the determination of the critical properties, and use $T_{b}$ and $S G$ as the input parameters.

On the other hand, the critical volume $\left(V_{c}\right)$ and acentric factor $\left(\omega_{a c}\right)$ are parameters that are not measured directly and can be obtained from accurate values for $T_{c}$ and $P_{c}$ using methods available in the literature described in Equations (18-20) from Table 3. 
TABLE 1

Summary of average boiling points for a multicomponent mixture

\begin{tabular}{|c|c|c|}
\hline Average Boiling Point & Correlation & Equations \\
\hline Volumetric Average Boiling Point (VABP) & $V A B P=\sum_{i=1}^{n} x_{v i} T_{b i}$ & (2) \\
\hline Molar Average Boiling Point (MABP) & $M A B P=\sum_{i=1}^{n} x_{m i} T_{b i}$ & (3) \\
\hline Weight Average Boiling Point (WABP) & $W A B P=\sum_{i=1}^{n} x_{w i} T_{b i}$ & (4) \\
\hline Cubic Average Boiling Point ${ }^{*}(C A B P)$ & $C A B P=\left(\frac{1}{1.8}\right)\left[\sum_{i=1}^{n} x_{v i}\left(1.8 T_{b i}-459.67\right)^{1 / 3}\right]^{3}+255.37$ & (5) \\
\hline Mean Average Boiling Point ${ }^{\ddagger}(M e A B P)$ & $M e A B P=\frac{M A B P+C A B P}{2}$ & (6) \\
\hline
\end{tabular}

$\ddagger$ Riazi (2004)

$n$ : number of components (or pseudocomponents); $i$ : component (or pseudocomponent); $x_{v i}$ : volume fraction of component (or pseudocomponent $i$ ); $x_{m i}$ : mole fraction of component (or pseudocomponent $i$ ); $x_{w i}$ : weight fraction of component (or pseudocomponent $i$ ); $T_{b i}$ : normal boiling point of pseudocomponent $i$ in Kelvin.

\subsection{Methods for Estimating the Thermophysical and Transport Properties}

In this section, methods available for estimating transport properties such as the kinematic viscosity $(v)$ and thermal conductivity $(\lambda)$, and thermal properties such as the specific heat capacity $\left(C_{p}\right)$ and vapor pressure $\left(P_{v a p}\right)$ of petroleum fractions are presented in Equations (21-29). These properties are essential for energy balances involved in chemical process unit and in the design of heat transfer equipment.

\subsubsection{Estimation of Transport Properties}

\section{Generalized Viscosity Correlations}

Numerous estimation methods have been presented by researchers to show the effect of temperature on the kinematic viscosity $(v)$. A review of viscosity estimation methods is given by Mehrotra et al. (1996) and some correlations with the use of $S G$ and $T_{b}$ as input data as in the present work, are presented in Equations (21-23) from Table 4.

\section{Thermal Conductivity-Temperature Correlations}

As in the case of kinematic viscosity $(v)$, the thermal conductivity $(\lambda)$ of high-boiling-point petroleum fractions (and its approach using the pseudoization method) is required in the thermal balance equations. The procedures suggested in this work comprises reliable correlations for predicting $\lambda$ values based on the input data and in the range of applicability of the property, as presented in Equations (24-26) from Table 5.

\subsubsection{Estimation of Thermal Properties}

\section{Specific Heat Capacity}

The specific heat capacity $\left(C_{p}\right)$ (of liquid phase) is required when modeling based on mass, momentum and energy balances is to be carried out. It is sensitive to temperature variations and depends mainly on the type of molecular structure of the compounds involved.

A summary of the calculation procedures used to estimate $C_{p}$ (of liquid phase) is presented in Equations (27-28) from Table 6. The input parameters are $K_{w}$ and $S G$.

\section{Vapor Pressure}

Methods for calculating the vapor pressure $\left(P_{\text {vap }}\right)$ of pure compounds or mixtures with known components are available in the book "The Properties of Gases and Liquids" (Poling et al., 2001) and in "The Design Institute for Physical Property Data - DIPPR" (Daubert et al., 2000), using predictive correlations developed from experimental data, such as the Antoine or Wagner equations. Most of the procedures used for petroleum fractions were suggested for a narrow boiling range or are applicable to mixtures with a known composition (Panteli et al., 2006). Nevertheless, a simple method for estimating the vapor pressure $\left(P_{v a p}\right)$ of highboiling-point petroleum fractions is presented in Equation (29) (Riazi, 2004).

$$
\begin{aligned}
& \log _{10}\left(1 \times 10^{5} P_{\text {vap }}\right)= \\
& 3.2041\left[1-0.998\left(\frac{T_{b}-41}{T-41}\right)\left(\frac{1393-T}{1393-T_{b}}\right)\right]
\end{aligned}
$$


TABLE 2

Summary of correlations to estimate $T_{c}, P_{c}$ and $M$

\begin{tabular}{|c|c|c|c|c|}
\hline Sources & Correlation & Input data & $\begin{array}{c}\text { Range of } \\
\text { applicability }\end{array}$ & Equations \\
\hline \multirow{3}{*}{$\begin{array}{l}\text { Winn } \\
(1955)\end{array}$} & $\ln \left(T_{c}\right)=-0.58779+4.2009\left(T_{b}^{0.08615}\right)\left(S G^{0.04614}\right)$ & $T_{b}, S G$ & NA & (9) \\
\hline & $P_{c}=10^{5}\left[6.148341 \times 10^{7}\left(T_{b}^{-2.3177}\right)\left(S G^{2.4853}\right)\right]$ & $T_{b}, S G$ & NA & (10) \\
\hline & $M=2.70579 \times 10^{-5}\left(T_{b}^{2.4966}\right)\left(S G^{-1.174}\right)$ & $T_{b}, S G$ & NA & (11) \\
\hline \multirow{3}{*}{$\begin{array}{l}\text { Riazi and } \\
\text { Daubert } \\
(1980)\end{array}$} & $T_{c}=35.9413\left[\exp \left(-6.9 \times 10^{-4} T_{b}-1.4442(S G)+4.91 \times 10^{-4}\left(T_{b} S G\right)\right)\right] T_{b}^{0.7293} S G^{1.2771}$ & $T_{b}, S G$ & $M>280 \mathrm{~kg} \cdot \mathrm{kmol}^{-1}$ & (12) \\
\hline & $P_{c}=10^{5}\left\{6.9575\left[\exp \left(-1.35 \times 10^{-2} T_{b}-0.3129(S G)+9.174 \times 10^{-3}\left(T_{b} S G\right)\right)\right] T_{b}^{0.6791} S G^{-0.6807}\right\}$ & $T_{b}, S G$ & $M>280 \mathrm{~kg} \cdot \mathrm{kmol}^{-1}$ & (13) \\
\hline & $M=42.965\left[\exp \left(2.097 \times 10^{-4} T_{b}-7.78712(S G)+2.08476 \times 10^{-3}\left(T_{b} S G\right)\right)\right] T_{b}{ }^{1.26007} S G^{4.98308}$ & $T_{b}, S G$ & $\begin{array}{l}70-700 \mathrm{~kg} \cdot \mathrm{kmol}^{-1} \\
300-850 \mathrm{~K}\end{array}$ & (14) \\
\hline \multirow{3}{*}{$\begin{array}{l}\text { Kesler } \\
\text { and Lee } \\
(1976)\end{array}$} & $T_{c}=189.8+450.6(S G)+[0.4244+0.1174(S G)] T_{b}+\frac{[0.1441-1.0069(S G)] 10^{5}}{T_{b}}$ & $T_{b}, S G$ & $\begin{aligned} & T_{b}>923 \mathrm{~K} \\
& 70-700 \mathrm{~kg} \cdot \mathrm{kmol}^{-1}\end{aligned}$ & (15) \\
\hline & $\ln \left(P_{c}\right)=10^{5}\left[\begin{array}{l}5.689-\frac{0.0566}{S G}-\left(0.43639+\frac{4.1216}{S G}+\frac{0.21343}{(S G)^{2}}\right) 0.001\left(T_{b}\right) \\
\left(\begin{array}{l}\left.0.47579+\frac{1.182}{S G}+\frac{0.15302}{(S G)^{2}}\right) \times 10^{-6}\left(T_{b}\right)^{2} \\
-\left(2.4505+\frac{9.9099}{(S G)^{2}}\right) \times 10^{-10}\left(T_{b}\right)^{3}\end{array}\right.\end{array}\right]$ & $T_{b}, S G$ & $\begin{array}{c}T_{b}>923 \mathrm{~K} \\
70-700 \mathrm{~kg} \cdot \mathrm{kmol}^{-1}\end{array}$ & (16) \\
\hline & $\begin{array}{l}M=-12272.6+9486.4(S G)+\left(8.3741-\frac{5.9917}{S G}\right) T_{b} \\
+\left[1-0.77084(S G)-0.02058(S G)^{2}\right]\left(0.7465-\frac{222.466}{T_{b}}\right) \frac{10^{7}}{T_{b}} \\
+\left[1-0.80882(S G)-0.02226(S G)^{2}\right]\left(0.3228-\frac{17.335}{T_{b}}\right) \frac{10^{12}}{\left(T_{b}\right)^{3}}\end{array}$ & $T_{b}, S G$ & $T_{b}<750 \mathrm{~K}$ & (17) \\
\hline
\end{tabular}

$T_{c}$ : critical temperature (or $T_{C N P S E}$ : pseudocritical temperature) (K); $P_{c}$ : critical pressure (or $P_{C N P S E}:$ pseudocritical pressure) (Pa); $M$ : molar mass (or $M_{N P S E}$ : molar mass of pseudocomponents) $\left(\mathrm{kg} \cdot \mathrm{kmol}^{-1}\right) ; T_{b}$ : boiling point $\left(T_{b i}\right.$ : normal boiling point of pseudocomponent $i$ or $M e A B P$ : Mean Average Boiling Point of whole fraction) (K); $S G$ : Specific Gravity; NA: not available. 
TABLE 3

Summary of correlations to estimate the $V_{c}$ (critical volume) and $\omega_{a c}$ (acentric factor)

\begin{tabular}{|c|c|c|c|c|}
\hline Sources & Correlation & Input data & $\begin{array}{l}\text { Range of } \\
\text { applicability }\end{array}$ & Equations \\
\hline Edmister (1958) & $\omega_{a c}=\frac{3}{7}\left(\frac{T_{b_{r}}}{1-T_{b_{r}}}\right)\left[\log _{10}\left(\frac{P_{c}}{101325}\right)\right]-1$ & $T_{b}, T_{c}, P_{c}$ & NA & (18) \\
\hline \multirow{2}{*}{$\begin{array}{l}\text { Lee and Kesler } \\
(1975) \\
\text { Kesler and Lee } \\
(1976)\end{array}$} & $\omega_{a c}=\frac{-\ln P_{r}-5.92714+6.09648 / T_{b_{r}}+1.28862 \ln T_{b_{r}}-0.169347 T_{b_{r}}{ }_{r}^{6}}{15.2518-15.6875 / T_{b_{r}}-13.4721 \ln T_{b_{r}}+0.43577 T_{b_{r}}{ }^{6}}$ & $T_{b}, T_{c}, K_{w}$ & $T_{b r}<0.8$ & (19) \\
\hline & $\begin{array}{c}\omega_{a c}=-7.904+0.1352 K_{w}-0.007465 K_{w}^{2}+ \\
8.359 T_{b_{r}}+\frac{1.408-0.01063 K_{w}}{T_{b_{r}}}\end{array}$ & $T_{b}, T_{c}, K_{w}$ & $T_{b r}>0.8$ & \\
\hline $\begin{array}{l}\text { Daubert and } \\
\text { Danner (1997) }\end{array}$ & $\begin{array}{l}V_{c}=\left(10^{-6}\right)\left\{\frac{83.14 T_{c}}{P_{c}\left[3.72+0.26\left(\alpha_{R}-7.00\right)\right]}\right\} \\
\alpha_{R}=5.811+4.919 \omega_{a c}\end{array}$ & $T_{c}, P_{c}, \omega_{a c}$ & NA & (20) \\
\hline
\end{tabular}

$V_{c}:$ critical volume (or $V_{c N P S E}:$ pseudocritical volume) $\left(\mathrm{m}^{3} . \mathrm{mol}^{-1}\right) ; T_{c}:$ critical temperature (or $T_{c N P S E}:$ pseudocritical temperature) (K); $P_{c}:$ critical pressure (or $P_{c N P S E}$ : pseudocritical pressure) (bar); $\omega_{a c}$ : acentric factor (or $\omega_{a c \_N P S E}$ pseudoacentric factor); $T_{b r}$ : reduced boiling point; $T_{b}$ : boiling point ( $T_{b i}$ : normal boiling point of pseudocomponent $i$ or $M e A B P$ : Mean Average Boiling Point of whole fraction) (K); SG: Specific Gravity; NA: not available.

TABLE 4

Summary of correlations to estimate the kinematic viscosity $(v)$

\begin{tabular}{|c|c|c|c|c|}
\hline Sources & Correlation & Input data & $\begin{array}{c}\text { Range of } \\
\text { applicability }\end{array}$ & Equations \\
\hline $\begin{array}{l}\text { Moharam et al. } \\
\text { (1995) }\end{array}$ & $\begin{array}{l}\ln \left[v\left(10^{-6}\right)\right]=A \exp \left[\left(\frac{T_{b}}{T}\right)(S G)^{B}\right]+C \\
A=1.0185 ; B=\frac{T_{b}}{305.078}-0.55526 ; C=-3.2421\end{array}$ & $T_{b}, S G, T$ & $323-823 \mathrm{~K}$ & (21) \\
\hline Mehrotra (1995) & $\begin{array}{l}\log \log \left[v\left(10^{-6}\right)+0.8\right]=a_{1}+a_{2} \log (T) \\
a_{1}=5.489+0.148\left(T_{b}\right)^{0.5} \\
a_{2}=-3.7\end{array}$ & $T_{b}, T$ & $323-823 \mathrm{~K}$ & (22) \\
\hline $\begin{array}{l}\text { Aboul-Seoud and } \\
\text { Moharam (1999a) }\end{array}$ & $\begin{array}{l}\ln \ln \left[v\left(10^{-6}\right)+0.8\right]=a_{1}+a_{2} \ln (T) \\
a_{1}=4.3414\left(T_{b} S G\right)^{0.2}+6.6913 \\
a_{2}=-3.7\end{array}$ & $T_{b}, S G, T$ & $323-823 \mathrm{~K}$ & (23) \\
\hline
\end{tabular}

v: kinematic viscosity $\left(\mathrm{m}^{2} \cdot \mathrm{s}^{-1}\right) ; T_{b}$ : boiling point ( $T_{b i}$ : normal boiling point of pseudocomponent $i$ or $M e A B P$ : Mean Average Boiling Point of whole fraction) (K); SG: Specific Gravity; $T$ : temperature $(\mathrm{K})$. 
TABLE 5

Summary of correlations to estimate the thermal conductivity $(\lambda)$

\begin{tabular}{|c|c|c|c|}
\hline Sources & Correlation & Input data & Equations \\
\hline Riazi and Faghri (1985) & $\lambda=\frac{\left.\left(1.11 / M^{1 / 2}\right)\left[3+20\left(1-T_{T}\right)_{c}\right)^{2 / 3}\right]}{3+20\left(1-T_{b} / T_{c}\right)^{2 / 3}}$ & $T_{b}, T_{c}, M, T$ & $(24)$ \\
\hline Lakshmi and Prasad (1992) & $\lambda=0.0655-0.00005 T+\frac{(1.3855-0.00197 T)}{M^{0.5}}$ & $M, T$ & (25) \\
\hline Aboul-Seoud and Moharam (1999b) & $\lambda=2.540312\left(\frac{S G}{T}\right)^{0.5}-0.014485$ & $S G, T$ & $(26)$ \\
\hline
\end{tabular}

$\lambda$ : thermal conductivity $\left(\mathrm{W} \cdot \mathrm{m}^{-1} . \mathrm{K}^{-1}\right) ; T_{c}$ : critical temperature (or $T_{c N P S E}$ : pseudocritical temperature) (K); $T_{b}$ : boiling point (or $T_{b b}$ : normal boiling point of pseudocomponent $i$ or $M e A B P$ : Mean Average Boiling Point of whole fraction) (K); $S G$ : Specific Gravity; $M$; molar mass; $T$ : temperature (K); NA: not available.

TABLE 6

Summary of correlations to estimate the specific heat capacity $\left(C_{p}\right)$ in liquid phase

\begin{tabular}{|c|c|c|c|c|}
\hline Sources & Correlation & Input data & $\begin{array}{c}\text { Range of } \\
\text { applicability }\end{array}$ & Equations \\
\hline $\begin{array}{l}\text { Watson and } \\
\text { Nelson (1933) }\end{array}$ & $\begin{array}{l}C_{p}=\left(10^{3}\right)\left(0.28299+0.23605 K_{w}\right) \\
\times\left[\begin{array}{l}0.645-0.05959(S G)+ \\
(2.32056+0.94752(S G))\left(\frac{T}{1000}-0.25537\right)\end{array}\right]\end{array}$ & $K_{w}, S G, T$ & NA & (27) \\
\hline $\begin{array}{l}\text { Kesler and Lee } \\
\text { (1976) }\end{array}$ & $\begin{array}{l}C_{p}=A_{1}+A_{2} T+A_{3} T^{2} \\
A_{1}=\left[\begin{array}{l}-4.90383+(0.099319+0.104281(S G)) K_{w}+ \\
\frac{4.81407-0.194833 K_{w}}{S G}\end{array}\right]\left(10^{3}\right) \\
A_{2}=\left(10^{-1}\right)\left(7.53624+6.214610 K_{w}\right)\left(1.12172-\frac{0.27634}{S G}\right) \\
A_{3}=-\left(10^{-4}\right)\left(1.35652+1.11863 K_{w}\right)\left(2.9027-\frac{0.70958}{S G}\right)\end{array}$ & $K_{w}, S G, T$ & $T_{b r}<0.8$ & (28) \\
\hline
\end{tabular}

$C_{p}$ : specific heat capacity $\left(\mathrm{J} . \mathrm{kg}^{-1} \cdot \mathrm{K}^{-1}\right) ; S G$ : Specific Gravity; $T$ : Temperature $(\mathrm{K}) ; T_{b}$ : boiling point (or $T_{b i}$ : normal boiling point of pseudocomponent $i$ or MeABP: Mean Average Boiling Point of whole fraction) (K). NA: not available.

where, $P_{\text {vap }}$ is the vapor pressure $(\mathrm{Pa}) ; T_{b}$ is the boiling point $\left(T_{b i}\right.$ : normal boiling point of pseudocomponent $i$ or $M e A B P$ : Mean Average Boiling Point of the whole fraction) (K); and $T$ is the temperature $(\mathrm{K})$.

\section{COMPUTATIONAL FRAMEWORK}

\subsection{High-Boiling-Point Petroleum Fractions Samples and Data Requirements}

High-boiling-point petroleum fractions are characterized by their $S G$ or API gravity and BP curve, parameters well established in the ASTM D 287 (2006), ASTM D 1298 (2005) and ASTM D 2892 (2005) standard methods, respectively. Three Brazilian crude oils with different API gravities $\left(16-25^{\circ} \mathrm{API}\right)$, obtained from separate sources, and distilled by conventional atmospheric distillation (ASTM D 2892, 2005), providing three atmospheric distillation residues (ATR-W, ATR-Y and ATR-Z), were studied in the present work. The BP curves were obtained in the Petrobras Research and Development Center (CENPES-Brazil) and are represented by pairs of points of accumulated distilled volume versus temperature as presented in Table 7. 
TABLE 7

Boiling point curve and the density of the whole high-boiling-point petroleum fractions

\begin{tabular}{|c|c|c|c|c|c|}
\hline \multicolumn{2}{|c|}{$\begin{array}{c}\text { ATR-W } \\
952.2 \mathrm{~kg} \cdot \mathrm{m}^{-3}\end{array}$} & \multicolumn{2}{|c|}{$\begin{array}{c}\text { ATR-Y } \\
914.4 \mathrm{~kg} \cdot \mathrm{m}^{-3}\end{array}$} & \multicolumn{2}{|c|}{$\begin{array}{c}\text { ATR-Z } \\
903.8 \mathrm{~kg} \cdot \mathrm{m}^{-3} \\
\end{array}$} \\
\hline $\begin{array}{l}\text { Accumulate volume } \\
\text { of distillate }(\% \mathrm{v} / \mathrm{v})\end{array}$ & $\begin{array}{c}\text { Boiling } \\
\text { temperature }(\mathrm{K})\end{array}$ & $\begin{array}{l}\text { Accumulate volume } \\
\text { of distillate }(\% \mathrm{v} / \mathrm{v})\end{array}$ & $\begin{array}{c}\text { Boiling } \\
\text { temperature }(\mathrm{K})\end{array}$ & $\begin{array}{l}\text { Accumulate volume } \\
\text { of distillate }(\% \mathrm{v} / \mathrm{v})\end{array}$ & $\begin{array}{c}\text { Boiling } \\
\text { temperature }(\mathrm{K})\end{array}$ \\
\hline 3.31 & 459.1 & 38.21 & 653.2 & 3.5 & 377.15 \\
\hline 10.70 & 551.2 & 41.45 & 680.2 & 4.2 & 398.15 \\
\hline 19.87 & 647.2 & 42.79 & 693.2 & 5.4 & 423.15 \\
\hline 24.80 & 670.2 & 46.41 & 700.2 & 7.5 & 448.15 \\
\hline 30.83 & 693.2 & 47.36 & 706.2 & 10.9 & 493.15 \\
\hline 34.13 & 710.2 & 49.69 & 716.2 & 14.1 & 519.15 \\
\hline 31.98 & 720.2 & 52.88 & 723.2 & 14.6 & 523.15 \\
\hline 35.29 & 733.2 & 56.86 & 726.2 & 18.0 & 546.15 \\
\hline 38.54 & 748.2 & 61.75 & 733.2 & 21.0 & 566.15 \\
\hline 40.81 & 768.2 & 66.32 & 746.2 & 24.7 & 589.15 \\
\hline 42.66 & 773.2 & 70.89 & 762.2 & 27.8 & 611.15 \\
\hline 45.03 & 790.2 & 72.33 & 773.2 & 30.9 & 633.15 \\
\hline 47.38 & 801.2 & & & 33.9 & 653.15 \\
\hline 49.65 & 810.2 & & & 37.0 & 673.15 \\
\hline 51.36 & 813.2 & & & 39.9 & 692.15 \\
\hline 51.93 & 818.2 & & & 42.7 & 705.15 \\
\hline 60.59 & 818.4 & & & 45.5 & 711.15 \\
\hline 62.35 & 846.3 & & & 46.2 & 713.15 \\
\hline 65.24 & 880.0 & & & 49.0 & 728.15 \\
\hline 69.62 & 920.3 & & & 51.7 & 743.15 \\
\hline 73.81 & 967.9 & & & 54.4 & 753.15 \\
\hline & & & & 56.9 & 763.15 \\
\hline & & & & 58.6 & 778.15 \\
\hline & & & & 61.5 & 788.15 \\
\hline & & & & 63.6 & 807.15 \\
\hline & & & & 65.9 & 823.15 \\
\hline & & & & 68.7 & 837.15 \\
\hline & & & & 71.3 & 839.15 \\
\hline
\end{tabular}

\subsection{Pseudocomponent Breakdown Methodology}

The range of the BP curve was cut in order to obtain non-overlapping temperature intervals, continuously covering the temperature range according to the integral mean temperature of the corresponding interval of the distilled fraction (Eckert and Vaněk, 2005).

Whitson and Brulé (2000) and Eckert and Vaněk (2005) pointed out that it is sufficient to use about $15 \mathrm{~K}$ for normal boiling points up to $700 \mathrm{~K}$, about $30 \mathrm{~K}$ for between 700 and $950 \mathrm{~K}$ and about $50 \mathrm{~K}$ for higher boiling point mixtures. Thus, each temperature interval represents one pseudocomponent with a normal boiling point, defined by the integral mean temperature over the corresponding interval of the distilled fraction, as described in Equations (30-31) (Eckert and Vaněk, 2005; Miquel and Castells, 1993; Beer, 1994).

$$
\begin{gathered}
T_{b i}=\frac{T_{T B P}\left(x_{v i}^{R_{s}}\right)+T_{T B P}\left(x_{v i}^{L_{s}}\right)}{2} \\
T_{b i}=\frac{1}{x_{v i}^{R_{s}}-x_{v i}^{L_{s}}} \int_{x_{v i}^{L_{s}}}^{x_{v i}^{R_{s}}} T_{T B P}\left(x_{v}\right) d x_{v}
\end{gathered}
$$

where $i$ is the component (or pseudocomponent); $x_{v i}$ is the volume fraction of the component (or pseudocomponent $i$ ) on 
the left side $\left(L_{s}\right)$ and on the right side $\left(R_{s}\right)$ in the boiling range; and $T_{b i}$ is the normal boiling point of pseudocomponent $i$ in Kelvin.

\subsection{Correlations and Predictive Technique Availability}

In this study, a pseudoization method is presented to relate the basic properties (boiling point $\left(T_{b}\right)$, Specific Gravity $(S G)$ and Watson factor characterization $\left(K_{w}\right)$ ), to the thermodynamic properties (critical temperature $\left(T_{c}\right)$, critical pressure $\left(P_{c}\right)$, critical volume $\left(V_{c}\right)$ and acentric factor $\left.\left(\omega_{a c}\right)\right)$ and to thermophysical and transport properties (thermal conductivity $(\lambda)$, specific heat capacity $\left(C_{p}\right)$, kinematic viscosity $(v)$ and vapor pressure $\left(P_{\text {vap }}\right)$ ) of high-boiling-point petroleum fractions.

The development of the pseudocomponent approach presented in this work was based on the procedure suggested by Lion and Edmister (1975) and Miquel and Castells (1994, 1993), assuming $K_{w}$ to be constant, that is, the same for each pseudocomponent and calculated using Equation (7). Thus, the liquid density $\left(\rho_{i}\right)$ (at $288.75 \mathrm{~K}$ ) of each pseudocomponent (NPSE) could be estimated using Equation (32) (Miquel and Castells, 1994, 1993).

$$
\rho_{i}=\rho_{N P S E_{i}}=1215.253 \frac{T_{b i}^{1 / 3}}{K_{w}}
$$

In the computational approach, an optimization subroutine was introduced to estimate the best set of thermodynamic properties $\left(T_{c}, P_{c}\right.$ and $\left.M\right)$ based on minimization of the material balance error as described in the next section.

\section{Computational Procedure Description}

The computational tool used to develop the pseudoization computational approach and to analyze the physicochemical properties of the high-boiling-point petroleum fractions was built up in FORTRAN-90 language using Compaq Visual FORTRAN compiler (professional edition 6.6). It is organized in seven (07) environments as presented in Figure 1 and described as follows.

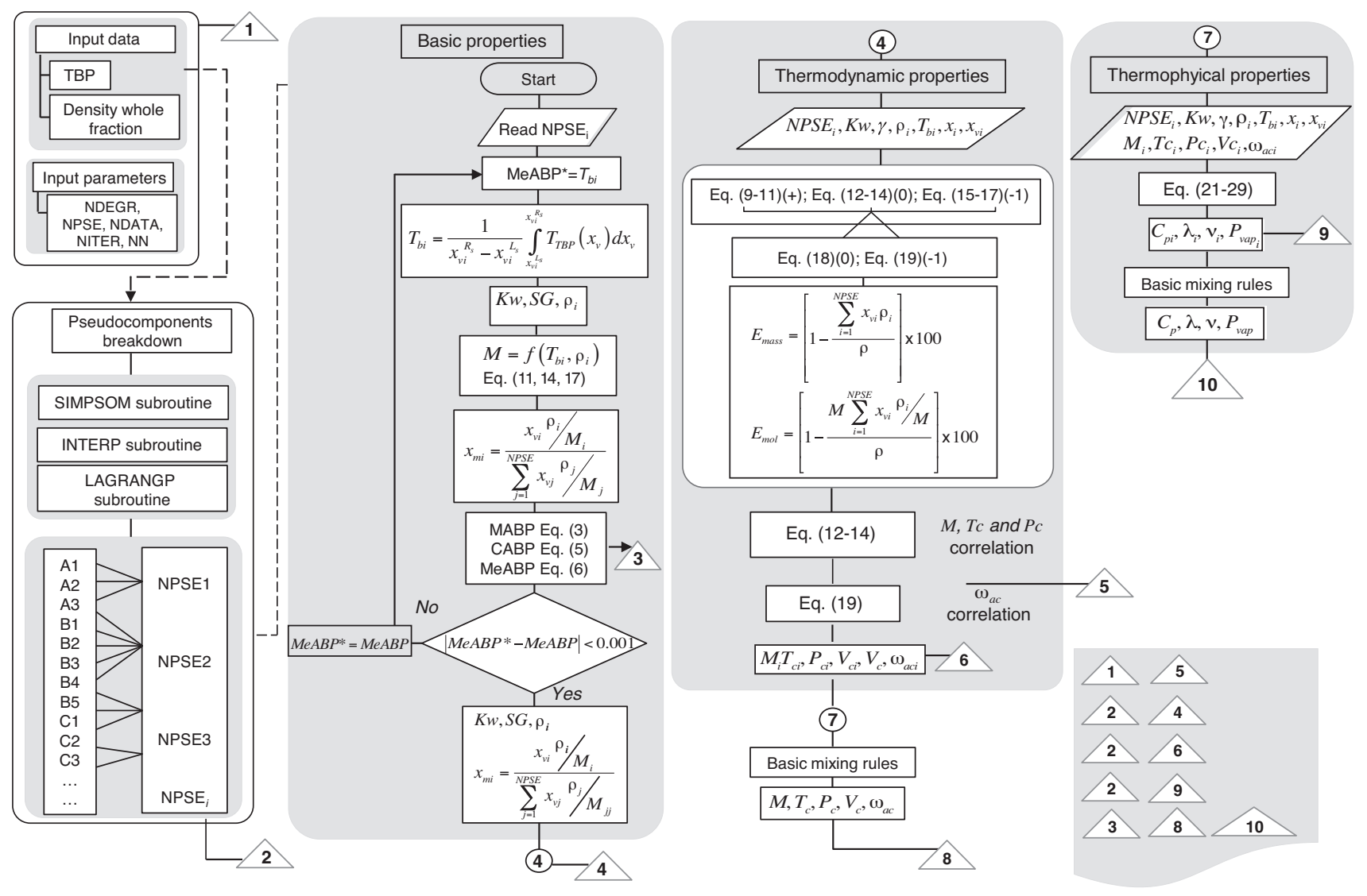

Figure 1

Computational environment to estimate the basic, the thermodynamic and the thermophysical properties of heavy petroleum fractions. 
High-boiling-point Petroleum Fractions Data

Environment-Input Data

The user has to introduce the BP distillation data and the whole fraction density.

\section{Internal Procedures Data Environment-Input Parameter}

Within the computational framework some information is required in order to apply the numerical methods for interpolation, obtain the trial-and-error numerical solution and present information in the output report. Hence, the input parameter required are: Degree of Lagrange's interpolation polynomial (NDEGR) based on the fact that a polynomial fitting lower than third order defining the BP curve is recommended as a procedure to estimate the accumulated distilled volume values for each distilling temperature (Pasquini and Bueno, 2007); number of pseudocomponents (NPSE); number of input data for the BP data (NDATA), maximum number of iterations (NITER), total interpolated data on BP curve to be presented in output report (NN).

\section{Pseudocomponent Breakdown Environment}

This environment computes the integral boiling point $\left(T_{b i}\right)$ using Equation (31). It consists of three subroutines called: SIMPSON, INTERP and LAGRANP (Miquel and Castells, 1994, 1993).

\section{Basic Characterization Environment}

The procedure for estimating the basic properties is described in Miquel and Castells (1993) as follows:

- stage 1: compute the $T_{b i}$ of each pseudocomponent predefined in the input data parameters environment, using Equation (31);

- stage 2: this subroutine requires a starting value for the mean average boiling point $(M e A B P)$ as follows:

$$
M e A B P^{*}=T_{b i}
$$

- stage 3: estimate $K_{w}(E q .7)$ and the pseudocomponent liquid density $\left(\rho_{i}\right)(E q .32)$ based on the starting value for $M e A B P^{*}$;

- stage 4: calculate the molar $\left(x_{m i}\right)$ fraction of each pseudocomponent ( $i$ ) using the correlation in Equation (34) as follows:

$$
x_{m i}=\frac{x_{v i} \rho_{i} / M_{i}}{\sum_{j=1}^{N P S E} x_{v j} \rho_{j} / M_{j j}}
$$

- stage 5: calculate the Molar-, Cubic- and Mean-Average Boiling Points (MABP, CABP and $M e A B P$ ) of the whole fraction using Equations $(3,5,6)$ in Table 1 ;

- stage 6: if the absolute difference between the MeABP value obtained in stage 5 and stage 1 is larger than 0.001 , assign the new value for $M e A B P$ obtained in stage 5 and go back to step stage 1; on convergence, then proceed to stage 7;
- stage 7: Assign the normal boiling point $\left(T_{b i}\right)$, density $\left(\rho_{i}\right)$, volume, and molar concentrations $\left(x_{v i}\right.$ and $x_{m i}$, respectively) to each pseudocomponent.

\section{Thermodynamic Characterization Environment}

The thermodynamic properties $\left(M, T_{c}\right.$ and $\left.P_{c}\right)$ and acentric factor $\left(\omega_{a c}\right)$ are estimated from correlations shown in Tables 2-3, which are denoted according to the coded numbers: -1 , 0 or 1 for $M, T_{c}$ and $P_{c}$, respectively, and -1 or 0 for the $\omega_{a c}$ correlations (Tab. 8).

TABLE 8

Coded correlations for estimation of thermodynamic properties

\begin{tabular}{l|c|l}
\hline \multicolumn{1}{c|}{ Thermodynamic property } & $\begin{array}{c}\text { Coded } \\
\text { number }\end{array}$ & Correlation \\
\hline & -1 & Kesler and Lee (1976) \\
Critical properties set $\left(T_{c}, P_{c}, M\right)$ & 0 & Riazi and Daubert (1980) \\
& 1 & Winn (1955) \\
\hline & -1 & Kesler and Lee (1976) \\
Acentric factor $\left(\omega_{a c}\right)$ & 0 & Lee and Kesler (1975) \\
& 0 Edmister (1958) \\
\hline
\end{tabular}

Aiming to obtain the best set of correlations, an optimization subroutine for minimization of the mass- and molar-balance errors was included. Hence, based on a set of twenty five (25) pseudocomponents, all possible combinations between these correlations were defined (see Fig. 2). From the subroutine for basic properties estimation, assigned the normal boiling point $\left(T_{b i}\right)$, density $\left(\rho_{i}\right)$, volume, and molar concentrations $\left(x_{v i}\right.$ and $x_{m i}$, respectively) to each pseudocomponent, compute critical properties $\left(T_{c i}\right.$ and $\left.P_{c i}\right)$, acentric factor $\left(\omega_{a c i}\right)$, molar mass $\left(M_{i}\right)$ and Watson's characterization factor $\left(K_{w}\right)$ of the pseudocomponent and compute whole fraction critical properties $\left(T_{c}\right.$ and $\left.P_{c}\right)$, acentric factor $\left(\omega_{a c}\right)$ and molar mass $(M)$ using $M e A B P$ and $\rho$.

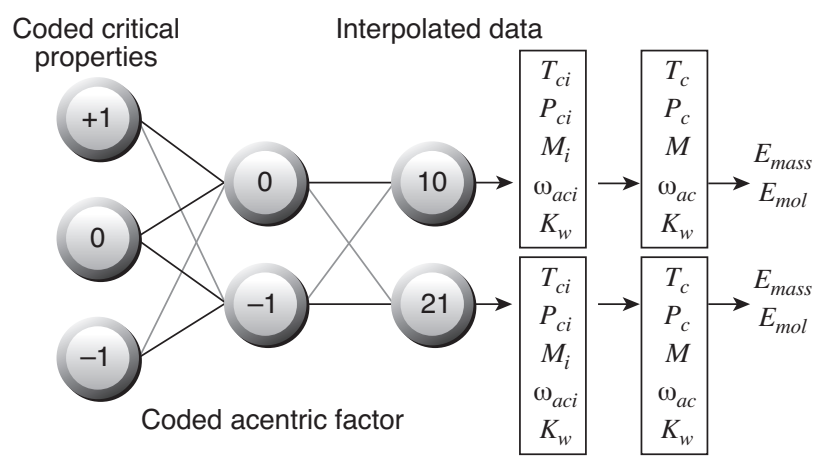

Figure 2

Sketch for optimization procedure to estimate the thermodynamic properties of the pseudocomponents $\left(T_{c i}, P_{c i}\right.$, $M_{i}, \omega_{a c i}$ and $\left.K_{w}\right)$ and whole fraction $\left(T_{c}, P_{c}, M, \omega_{a c}\right.$ and $\left.K_{w}\right)$. 
Subsequent, compute the pseudocomponent-breakdown mass- and molar-balance error using Equations $(35,36)$ (Beer, 1994; Miquel and Castells, 1994, 1993) as follows:

$$
\begin{gathered}
E_{\text {mass }}=\left[1-\frac{\sum_{i=1}^{N P S E} x_{v i} \rho_{i}}{\rho}\right] \times 100 \\
E_{\text {mol }}=\left[1-\frac{M \sum_{i=1}^{N P S E} x_{v i} \rho_{i} / M}{\rho}\right] \times 100
\end{gathered}
$$

At this stage, the solution was reached when the mass- and molar-balance errors were minimized. Table 9 presents the result obtained for the ATR-W and analogous data were obtained for ATR-Y and ATR-Z.

\section{TABLE 9}

Mass- and molar-balance errors calculated from optimization procedure using coded critical properties and coded acentric factor

\begin{tabular}{c|c|c|c|c}
\hline \multicolumn{5}{c}{ Case study: ATR-W } \\
\hline $\begin{array}{c}\text { Coded critical } \\
\text { property }\end{array}$ & Coded $\omega_{a c}$ & $\begin{array}{c}\text { Interpolated } \\
\text { data }\end{array}$ & $E_{\text {mass }}$ & $E_{\text {mol }}$ \\
\hline-1 & -1 & 21 & 1.37 & 27.45 \\
-1 & 0 & 21 & 1.37 & 27.45 \\
-1 & -1 & 10 & 1.40 & 26.94 \\
-1 & 0 & 10 & 1.40 & 26.94 \\
0 & -1 & 21 & 2.73 & 8.60 \\
0 & 0 & 21 & 2.73 & 8.60 \\
0 & -1 & 10 & 2.71 & 8.52 \\
0 & 0 & 10 & 2.71 & 8.52 \\
1 & -1 & 21 & 3.09 & 10.08 \\
1 & 0 & 21 & 3.09 & 10.08 \\
1 & -1 & 10 & 3.07 & 9.97 \\
1 & 0 & 10 & 3.07 & 9.97 \\
\hline
\end{tabular}

$\omega_{a c}:$ acentric factor; $E_{\text {mass }}:$ error in mass balance; $E_{\text {mol }}$ : error in molar balance.

On the other hand, mass- and molar-balance error were analyzed. Hence, the results for the mass- and molar-balance errors $\left(E_{\text {mass }}\right.$ and $\left.E_{\text {mol }}\right)$ presented in Table 9 for the ATR-W case study showed that the choice of $\omega_{a c}$ correlation appears to have no influence on the reliability of the thermodynamic properties. Following, considering the Kesler and Lee (1976) and Lee and Kesler (1975) correlation, coded with -1 , for the estimation of $\omega_{a c}$, analyses were performed establishing the possible combinations among the set of correlations to estimate the thermodynamic properties $\left(M, T_{c}\right.$ and $\left.P_{c}\right)$ and the number of interpolated data on the BP curve (input data) being ten (10) or twenty one (21).
In order to accomplish the best set of correlations, data from $E_{\text {mass }}$ and $E_{m o l}$ constituted an array of two vectors (called mass_vector and molar_vector) which were used in a subroutine to choose the minimum value in the arrays.

\section{Thermophysical and Transport Characterization Environment}

A final subroutine estimates the thermal conductivity $(\lambda)$, the specific heat capacity $\left(C_{p}\right)$ the kinematic viscosity $(v)$ and the vapor pressure $\left(P_{\text {vap }}\right)$ of each pseudocomponent as a function of the temperature $(T)$, using the normal boiling point $\left(T_{b i}\right)$ (for pseudocomponents) or $M e A B P$ (for whole fractions) as the input data. The methods presented in Equations (21-28) from Tables 4-6 and Equation (29) are included in this module.

\section{Reliability of the Pseudoization Approach Environment}

The success of the method is based on the accuracy of the empirical or semi-empirical correlations in the literature and the standard industrial methods. Hence, the reliability of the basic and thermodynamic properties is calculated from the mass and molar balance equations (Eq. 35, 36) (Beer, 1994; Miquel and Castells, 1994, 1993). The thermophysical properties were compared with the experimental data obtained in the research laboratories using the methods described in the next section. Data computed were evaluated in terms of Average Absolute Deviation $(A A D \%)$ which is define as a relation among the absolute deviation of estimating a quantity divided by its experimental value $\left(y_{i, r e f}\right)$ as presented in Equation (1).

\section{EXPERIMENTAL DATA}

\subsection{Thermal Analyses: Differential Scanning Calorimetry (DSC)}

The DSC experiments were carried out on the high-boilingpoint petroleum fractions using a Mettler-Toledo DSC $823^{\mathrm{e}}$ thermal analysis system (Mettler Toledo $\mathrm{GmbH}$, Germany), and liquid nitrogen was used for cooling. The DSC module was calibrated with indium standard (It had a certified fusion temperature of $156.6 \pm 0.3^{\circ} \mathrm{C}$ and heat flow calibration of

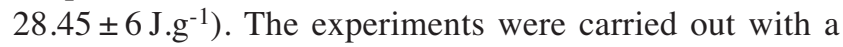
sample size of $\sim 10 \mathrm{mg}$. The samples were weighed into open aluminum pans, hermetically sealed and then placed in the sample chamber of the DSC module. The reference was an identical, empty pan, with an equal weight matched within $\pm 0.1 \mathrm{mg}$. A linear heating rate of $25 \mathrm{~K} \cdot \mathrm{min}^{-1}$ was used over the temperature range from 350 to $600 \mathrm{~K}$, with a nitrogen flow of $50 \mathrm{~mL} \cdot \mathrm{min}^{-1}$ controlled by a gas control system (Mettler-Toledo TS0800GC1). The STAR $(\mathrm{V}$ 9.01) software was used to provide an estimate of the enthalpy $(\Delta H)$, the heat flow and specific heat capacity. 
In order to evaluate the repeatability of the measurement, the Relative Standard Deviation (\%RSD) with respect to the mean signal of each measurement, calculated over three (03) consecutive repetitions of Indium standard was examined. The value obtained was lower than $8.53 \%$.

\subsection{Rheological Measurements}

The rheological analyses were carried out in a Thermo Scientific Haake Rheostress 6000 rotational rheometer (Gebrüder HAAKE GmbH, Germany) interfaced with an electric cone heating system UTCE/C, using 2 parallel plates of $0.035 \mathrm{~m}$ and setting the gap set at $1.0 \times 10^{-3} \mathrm{~m}$.

Two measuring techniques were applied. The first rheological measurements refers to the analyses of transition between pseudoplastic and Newtonian flow obtained from an analysis of the flow curve prepared using the controlled rate mode at 383.15 and $363.15 \mathrm{~K}$ and at the shear rate range from 10 to $700 \mathrm{~s}^{-1}$ with measurements being made every $10 \mathrm{~s}^{-1}$. The flow behavior and dynamic viscosity $(\mu)$ of the ATR-W, ATR-Y and ATR-Z was investigated over a wide range of shear rates at $383.15 \mathrm{~K}$ (for ATR-W) and $363.15 \mathrm{~K}$ (for ATR-Y and ATR-Z). Three runs were done for each material, and the resulting shear stress was the three experimental averages values. The results were recorded and fitted to the Newtonian models.

The experimental data were evaluated and fitted according to the rheological Newtonian model, using the average shear stress $(\tau)$ value for each shear rate $(\sigma)$. High-boiling-point petroleum fractions found to follow Newtonian behavior based on the yield stress of the oils (Tab. 10). It can be observed that the shear stress is proportional to the shear rate (Newtonian behavior) which mean that the dynamic viscosity $(\mu)$ is constant and independent from the shear rate at constant temperature (test temperature).

The other rheological measurement was focus on the sweep measurements in the temperature range from $473.15 \mathrm{~K}$ to $343.15 \mathrm{~K}$ with the heating rates of $2 \mathrm{~K} \cdot \mathrm{min}^{-1}$ at constant frequency and constant shear stress $\left(100 \mathrm{~s}^{-1}\right)$. The temperature was controlled, in both cases, to allow a maximum deviation of $\pm 0.5 \mathrm{~K}$. All experiments were carried out using compressed air as the cooling fluid.

\section{RESULTS AND DISCUSSION}

\subsection{Simulated Boiling Point Data and Pseudocomponent Distribution}

The pseudocomponents were selected considering the need to represent the behavior of the mixture over the entire computational effort and availability of the input data. The most advantageous number of pseudocomponents to satisfactorily fit the data was determined by the trial-and-error exercise through applying a sensibility procedure in which the massand molar-balance errors were minimized. In this sense, Table 11 summarizes the sensibility exercise and establishes that twenty five (25) pseudocomponents are required to avoid excessive computational effort but guaranteeing the accuracy to estimate physicochemical properties of petroleum fractions.

The results in Figure 3 are presented to show the response of the computational approach using the pseudoization method with twenty five (25) pseudocomponents, in relation to the representation of the input data. Figure 3 shows the comparison between the simulated BP curve and the experimental data obtained from CENPES-PETROBRAS. The initial and final boiling points were set from 300 to $1300 \mathrm{~K}$ for ATR-W, from 650 to $800 \mathrm{~K}$ for ATR-Y, and from 350 and $850 \mathrm{~K}$ for ATR-Z, respectively.

The boiling point temperatures were evaluated in terms of Average Absolute Deviation ( $A A D \%$ ) where the absolute deviation was defined as the difference between the experimental value $\left(y_{i, r e f}\right)$ obtained from Petrobras Research and Development Center (CENPES-Brazil) and the response predicted by the modeling approach $\left(y_{i, c a l}\right)$ with the interpolation method, divided by its experimental value $\left(y_{i, r e f}\right)$. Figure 3 shows that with twenty five (25) pseudocomponents (each representing average boiling point ranges of $40 \mathrm{~K}, 6 \mathrm{~K}$ and $20 \mathrm{~K}$ for ATR-W, ATR-Y and ATR-Z, respectively) good agreement was obtained reporting an $A A D \%$ of just $1.74,0.89$ and $1.75 \%$ for ATR-W, ATR-Y and ATR-Z, respectively (Tab. 12).

It is of interest to note in Figure 3 that the simulated and experimental $\mathrm{BP}$ values, based on the chemical analysis, are effectively identical up to approximately $80 \% \mathrm{v} / \mathrm{v}$ distillation. Hence, the boiling temperature curve above $80 \% \mathrm{v} / \mathrm{v}$ and below $3 \% \mathrm{v} / \mathrm{v}$ of distillation, represented an extrapolation, and some possible deviations could occur, since there are no data to match them up. However, it can be seen that the results of the extrapolation still show the cubic polynomial trend of the experimental data provided by CENPESPETROBRAS, the volume fractions being arranged in a cumulative distribution of the volume fraction, as expected.

The methodology for distributing the complex bulk liquid into pseudocomponent compositions is shown in Figure 4. The results show that most of the components are concentrated in the first-cuts for ATR-W and ATR-Y (Fig. 4a,b), and in the end-cut for ATR-Z (Fig. 4c).

\subsection{Determination of the Basic and Thermodynamic Properties}

Properties of high-boiling-point petroleum fractions are estimated based on the computational procedure presented in this work, where the BP curve and the density of the whole fraction are the input bulk properties. The determination of the basic properties of the high-boiling-point petroleum 
TABLE 10

Yield stress $(\tau)$ and dynamic viscosity $(\mu)$ measurements of ATR-W at $383.15 \mathrm{~K}$, and ATR-Y and ATR-Z at $363.15 \mathrm{~K}$ as functions of shear rate $(\sigma)$

\begin{tabular}{r|r|r|r|r|r|r}
\hline \multirow{2}{*}{$\sigma\left(\mathrm{s}^{-1}\right)$} & \multicolumn{2}{|c|}{ ATR-W } & \multicolumn{2}{|c|}{ ATR-Y } & \multicolumn{2}{|c}{ ATR-Z } \\
\cline { 2 - 7 } & $\tau(\mathrm{Pa})$ & $\mu(\mathrm{Pa} \cdot \mathrm{s})$ & $\tau(\mathrm{Pa})$ & $\mu(\mathrm{Pa} \cdot \mathrm{s})$ & $\tau(\mathrm{Pa})$ & $\mu(\mathrm{Pa} \cdot \mathrm{s})$ \\
\hline 10.0 & 6.4 & 0.639 & 5.6 & 0.561 & 3.4 & 0.340 \\
20.0 & 12.8 & 0.639 & 11.2 & 0.560 & 6.8 & 0.339 \\
30.0 & 19.2 & 0.639 & 16.8 & 0.560 & 10.2 & 0.339 \\
40.0 & 25.6 & 0.640 & 22.4 & 0.560 & 13.6 & 0.339 \\
50.0 & 32.0 & 0.639 & 27.9 & 0.559 & 17.0 & 0.340 \\
60.0 & 38.1 & 0.636 & 33.6 & 0.559 & 20.4 & 0.340 \\
70.0 & 44.5 & 0.636 & 39.2 & 0.560 & 23.9 & 0.342 \\
80.0 & 51.0 & 0.637 & 44.8 & 0.560 & 27.4 & 0.342 \\
90.0 & 57.2 & 0.635 & 50.4 & 0.560 & 30.9 & 0.343 \\
100.0 & 63.4 & 0.634 & 56.0 & 0.560 & 34.4 & 0.344 \\
110.0 & 69.6 & 0.633 & 61.5 & 0.559 & 37.9 & 0.345 \\
120.0 & 75.7 & 0.631 & 67.1 & 0.560 & 41.4 & 0.345 \\
130.0 & 82.0 & 0.631 & 72.7 & 0.559 & 44.9 & 0.346 \\
140.0 & 88.3 & 0.630 & 78.3 & 0.559 & 48.4 & 0.345 \\
150.0 & 94.5 & 0.630 & 84.0 & 0.560 & 51.9 & 0.346 \\
160.0 & 101.1 & 0.632 & 89.5 & 0.559 & 55.5 & 0.347 \\
170.0 & 107.4 & 0.632 & 95.2 & 0.560 & 59.0 & 0.347 \\
180.0 & 114.3 & 0.635 & 101.0 & 0.561 & 62.6 & 0.348 \\
190.0 & 121.0 & 0.637 & 106.5 & 0.560 & 66.2 & 0.348 \\
200.0 & 127.5 & 0.637 & 112.0 & 0.560 & 69.5 & 0.348 \\
210.0 & 133.9 & 0.638 & 117.7 & 0.560 & 72.9 & 0.347 \\
220.0 & 140.5 & 0.639 & 123.3 & 0.561 & 76.5 & 0.348 \\
230.0 & 146.7 & 0.638 & 128.9 & 0.561 & 80.1 & 0.348 \\
240.0 & 152.7 & 0.636 & 134.5 & 0.561 & 83.6 & 0.348 \\
250.0 & 159.3 & 0.637 & 140.2 & 0.561 & 87.1 & 0.348 \\
260.0 & 166.0 & 0.638 & 146.0 & 0.562 & 90.5 & 0.348 \\
270.0 & 173.0 & 0.641 & 151.8 & 0.562 & 94.2 & 0.349 \\
280.0 & 179.0 & 0.639 & 157.2 & 0.562 & 97.7 & 0.349 \\
290.0 & 185.4 & 0.639 & 162.8 & 0.562 & 101.1 & 0.349 \\
300.0 & 192.5 & 0.642 & 168.5 & 0.562 & 104.7 & 0.349 \\
310.0 & 199.0 & 0.642 & 174.0 & 0.561 & 108.2 & 0.349 \\
320.0 & 204.6 & 0.639 & 179.9 & 0.562 & 111.6 & 0.349 \\
\hline & 210.5 & 0.638 & 185.8 & 0.563 & 115.3 & 0.349 \\
\hline 350.0 & 216.2 & 0.636 & 191.4 & 0.563 & 118.9 & 0.350 \\
\hline & 222.6 & 0.636 & 197.3 & 0.564 & 122.1 & 0.349 \\
\hline & & & & & &
\end{tabular}

fractions involved the Cube of the Average Boiling Point $(C A B P)$, the Mean Average Boiling Point $(M e A B P)$, the Molar Average Boiling Point $(M A B P)$ and the Watson characterization factor $\left(K_{w}\right)\left(\right.$ Tab. 13). The $K_{w}$ is an approximate index of the paraffinicity of a petroleum fraction. The high values obtained for this index for ATR-W, ATR-Y and $\operatorname{ATRZ}\left(K_{w}=11.94, K_{w}=12.18\right.$ and $K_{w}=11.79$, respectively) indicated a high percent of pure saturated components and paraffin components.

Comparing the values of the average boiling points (Tab. 13), it appears that the $M e A B P$ was always lesser than

\begin{tabular}{l|l|l|l|l|l|l}
\hline \multirow{2}{*}{$\sigma\left(\mathrm{s}^{-1}\right)$} & \multicolumn{2}{|c|}{ ATR-W } & \multicolumn{2}{|c|}{ ATR-Y } & \multicolumn{2}{|c}{ ATR-Z } \\
\cline { 2 - 7 } & $\tau(\mathrm{Pa})$ & $\mu(\mathrm{Pa} \cdot \mathrm{s})$ & $\tau(\mathrm{Pa})$ & $\mu(\mathrm{Pa} \cdot \mathrm{s})$ & $\tau(\mathrm{Pa})$ & $\mu(\mathrm{Pa} \cdot \mathrm{s})$ \\
\hline 360.0 & 229.1 & 0.636 & 202.6 & 0.563 & 125.7 & 0.349 \\
370.0 & 234.5 & 0.634 & 208.0 & 0.563 & 129.3 & 0.350 \\
380.0 & 240.7 & 0.633 & 214.0 & 0.564 & 132.9 & 0.350 \\
390.0 & 246.6 & 0.632 & 219.5 & 0.563 & 136.5 & 0.350 \\
400.1 & 252.5 & 0.631 & 224.7 & 0.562 & 139.8 & 0.350 \\
410.0 & 260.6 & 0.636 & 230.1 & 0.562 & 143.3 & 0.350 \\
420.0 & 267.2 & 0.636 & 235.5 & 0.561 & 146.9 & 0.350 \\
430.0 & 273.0 & 0.635 & 240.7 & 0.560 & 150.3 & 0.350 \\
440.0 & 279.4 & 0.635 & 246.4 & 0.561 & 153.8 & 0.350 \\
450.0 & 285.9 & 0.635 & 251.9 & 0.560 & 157.7 & 0.351 \\
460.0 & 293.0 & 0.637 & 257.2 & 0.560 & 161.1 & 0.350 \\
470.0 & 298.5 & 0.635 & 262.9 & 0.560 & 164.4 & 0.350 \\
480.0 & 306.2 & 0.638 & 268.0 & 0.559 & 168.2 & 0.351 \\
490.0 & 312.4 & 0.638 & 273.6 & 0.559 & 171.6 & 0.350 \\
500.0 & 318.1 & 0.636 & 279.6 & 0.560 & 175.5 & 0.351 \\
510.0 & 324.1 & 0.635 & 285.1 & 0.560 & 178.9 & 0.351 \\
520.0 & 331.0 & 0.637 & 290.6 & 0.559 & 182.0 & 0.350 \\
529.9 & 336.5 & 0.635 & 295.8 & 0.559 & 185.7 & 0.351 \\
539.9 & 342.9 & 0.635 & 300.8 & 0.558 & 189.1 & 0.350 \\
549.9 & 349.7 & 0.636 & 306.3 & 0.557 & 192.5 & 0.350 \\
559.9 & 354.7 & 0.634 & 312.1 & 0.558 & 196.7 & 0.351 \\
570.0 & 360.2 & 0.632 & 317.4 & 0.557 & 200.0 & 0.351 \\
580.0 & 365.2 & 0.630 & 323.1 & 0.558 & 202.9 & 0.350 \\
590.0 & 370.3 & 0.628 & 328.9 & 0.558 & 206.6 & 0.350 \\
600.0 & 376.1 & 0.627 & 333.7 & 0.557 & 210.2 & 0.351 \\
610.0 & 381.9 & 0.626 & 339.2 & 0.557 & 213.5 & 0.350 \\
620.0 & 389.7 & 0.629 & 345.0 & 0.557 & 216.7 & 0.350 \\
629.9 & 396.5 & 0.629 & 350.0 & 0.556 & 220.2 & 0.350 \\
639.9 & 403.7 & 0.631 & 355.2 & 0.556 & 223.8 & 0.350 \\
649.8 & 410.0 & 0.631 & 360.0 & 0.555 & 227.1 & 0.350 \\
659.9 & 416.5 & 0.631 & 365.1 & 0.554 & 230.4 & 0.349 \\
669.9 & 423.2 & 0.632 & 370.7 & 0.554 & 234.0 & 0.350 \\
679.8 & 430.3 & 0.633 & 375.7 & 0.554 & 237.3 & 0.349 \\
& 434.6 & 0.630 & 380.4 & 0.552 & 240.5 & 0.349 \\
& 439.5 & 0.628 & 386.2 & 0.553 & 244.2 & 0.349 \\
\hline & & & & & &
\end{tabular}

the $C A B P$, since the relationship between the density and molar mass increased as the boiling point decreased. This implies in an increase in the relative importance of the fractions with lower boiling points and lower average molar masses, reducing the value of the $M e A B P$. Conversely, $M e A B P$ was lager than $M A B P$, and thus there was a relative increase in the importance of the fractions with higher boiling points due to the increase in density with increase in boiling point. Moreover, it is important to estimate the average boiling points, and specifically the $M e A B P$, for use in the correlations used to estimate the various thermodynamic and thermophysical properties. 
TABLE 11

Summary of trial-and-error exercise for optimizing the number of pseudocomponents

\begin{tabular}{r|c|r|c|c|c|c}
\hline \multirow{2}{*}{ NPSE } & \multicolumn{2}{|c|}{ ATR-W } & \multicolumn{2}{c|}{ ATR-Y } & \multicolumn{2}{c}{ ATR-Z } \\
\cline { 2 - 7 } & $E_{\text {mass }}$ & $E_{\text {mol }}$ & $E_{\text {mass }}$ & $E_{\text {mol }}$ & $E_{\text {mass }}$ & $E_{\text {mol }}$ \\
\hline 5 & 4.76 & 12.71 & 3.02 & 4.63 & 2.79 & 3.80 \\
10 & 4.10 & 10.37 & 2.78 & 3.25 & 2.27 & 3.41 \\
15 & 3.26 & 9.04 & 2.39 & 2.91 & 2.00 & 3.01 \\
20 & 2.84 & 8.55 & 1.27 & 2.22 & 1.76 & 2.92 \\
25 & 2.73 & 8.60 & 0.71 & 2.03 & 1.12 & 2.92 \\
30 & 2.69 & 8.60 & 0.71 & 1.99 & 1.12 & 2.92 \\
50 & 2.66 & 8.60 & 0.70 & 1.99 & 1.12 & 2.92 \\
\hline
\end{tabular}

NPSE: number of pseudocomponents; $E_{\text {mass }}$ : error in mass balance; $E_{\text {mol }}:$ error in molar balance.

\subsubsection{Density and Molar Mass Distributions in the Pseudocomponents}

On the other hand, both the molar mass $(M)$ and the density ( $\rho)$ are fundamental physical properties that can be used in conjunction with other physical properties to characterize the ATR-W, ATR-Y and ATR-Z petroleum fractions. Figure 5 presents the values for molar mass $\left(M_{N P S E}\right)$ and density $\left(\rho_{\text {NPSE }}\right)$ as a function of the normal boiling point $\left(T_{b i}\right)$ for the pseudocomponents. From Figure 5a, it is evident that, in the case of ATR-W, both these properties increase with an increment in $T_{b i}$.

However, Figure 5 also shows that the value for $M_{N P S E}$ decreases significantly as the density of the fraction increases, which is followed by a more gradual change in $M_{N P S E}$ with the increase in $\rho_{N P S E}$. Such behavior is to be expected since a high value for $T_{b i}$ corresponds to a high value for $M_{N P S E}$ and similarly a low $T_{b i}$ corresponds to a low $M_{N P S E}$.

\subsubsection{Critical Properties}

The availability of critical data for complex mixtures such as high-boiling-point petroleum fractions is insufficient, due to the experimental conditions required and the fact that they can not be measured directly (Korsten, 1998). In this study, a computational framework was presented with respect to reliable methods for predicting the critical properties based on the mass and molar balance errors (Eq. 35, 36).

\section{Reliable Critical Property Correlations}

Table 14 presents the available correlations introduced in this work, to estimate the critical properties (Eq. 9-17 from $T a b .2$ ) by means of a computational environment using the pseudocomponent approach, based on the fact that in predicting the $\omega_{a c}$, the choice of correlation appears to have no influence on the reliability of the thermodynamic properties. Hence, the results for the mass and molar balance errors $\left(E_{\text {mass }}\right.$ and $\left.E_{m o l}\right)$ presented in Table 14 for the ATR-W, ATR-Y and ATR $-Z$ case studies, are for a set of twenty five (25)
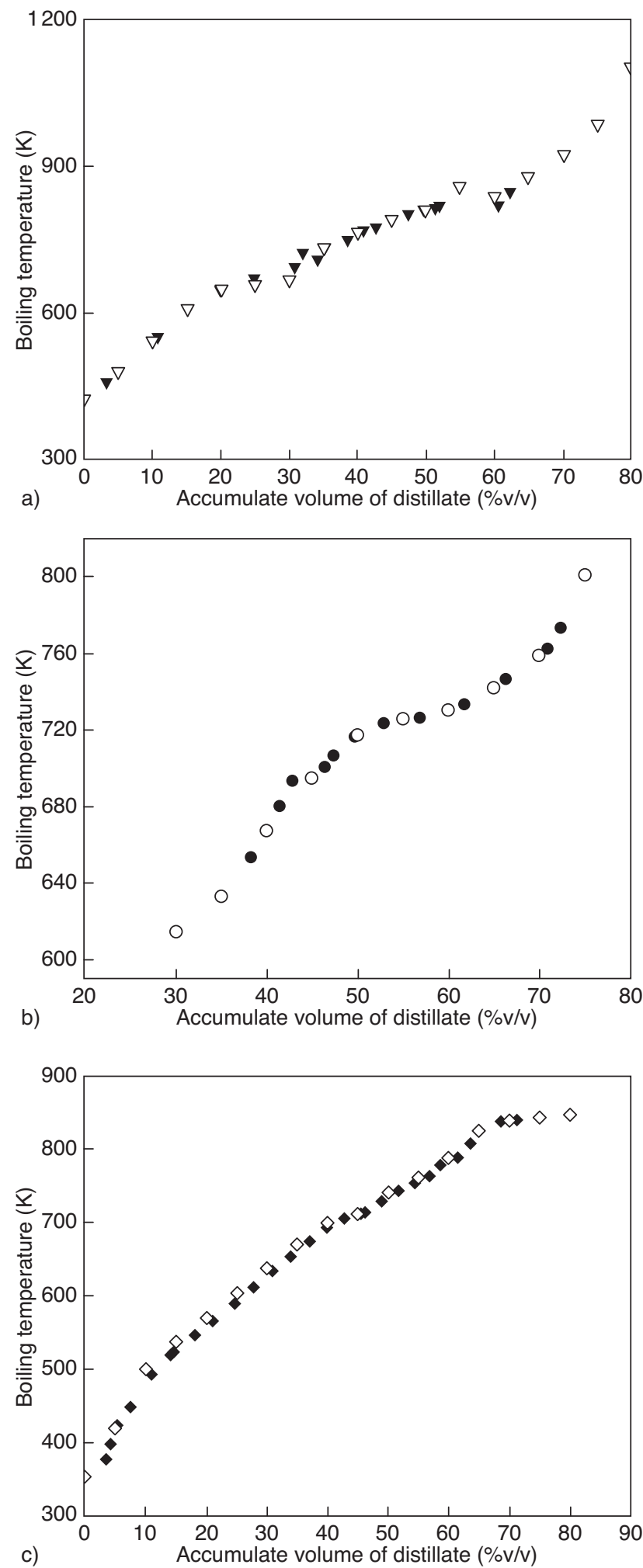

Figure 3

Boiling point curve of a) ATR-W ( $\nabla$ CENPES/Petrobras boiling point; $\nabla$ Simulated boiling point); b) ATR-Y ( CENPES/Petrobras boiling point; $\bigcirc$ Simulated boiling point), and c) ATR-Z ( CENPES/Petrobras boiling point; $\diamond$ Simulated boiling point). 
TABLE 12

Predicted boiling temperature and absolute deviations percent (\%) calculated by computational pseudocomponent approach for ATR-W, ATR-Y and ATR-Z

\begin{tabular}{|c|c|c|c|c|c|c|c|c|c|c|c|}
\hline \multicolumn{4}{|c|}{$\begin{array}{c}\text { ATR-W } \\
952.2 \mathrm{~kg} \cdot \mathrm{m}^{-3}\end{array}$} & \multicolumn{4}{|c|}{$\begin{array}{c}\text { ATR-Y } \\
914.4 \mathrm{~kg} \cdot \mathrm{m}^{-3}\end{array}$} & \multicolumn{4}{|c|}{$\begin{array}{c}\text { ATR-Z } \\
903.8 \mathrm{~kg} \cdot \mathrm{m}^{-3}\end{array}$} \\
\hline \multirow{2}{*}{$\begin{array}{c}\text { Accumulate } \\
\text { volume of } \\
\text { distillate } \\
(\% \mathrm{v} / \mathrm{v})\end{array}$} & \multicolumn{2}{|c|}{ Boiling temperature $(\mathrm{K})$} & \multirow{2}{*}{$\begin{array}{c}\text { Absolute } \\
\text { deviations } \\
\text { percent } \\
(\%)\end{array}$} & \multirow{2}{*}{$\begin{array}{c}\text { Accumulate } \\
\text { volume of } \\
\text { distillate } \\
(\% \mathrm{v} / \mathrm{v})\end{array}$} & \multicolumn{2}{|c|}{ Boiling temperature $(\mathrm{K})$} & \multirow{2}{*}{$\begin{array}{c}\text { Absolute } \\
\text { deviations } \\
\text { percent } \\
(\%)\end{array}$} & \multirow{2}{*}{$\begin{array}{c}\text { Accumulate } \\
\text { volume of } \\
\text { distillate } \\
(\% \mathrm{v} / \mathrm{v})\end{array}$} & \multicolumn{2}{|c|}{ Boiling temperature $(\mathrm{K})$} & \multirow{2}{*}{$\begin{array}{c}\text { Absolute } \\
\text { deviations } \\
\text { percent } \\
(\%)\end{array}$} \\
\hline & $\mid \begin{array}{c}\text { Experimental } \\
\left(y_{r e f}\right)\end{array}$ & $\begin{array}{l}\text { Predicted } \\
\quad\left(y_{c a l}\right)\end{array}$ & & & $\begin{array}{c}\text { Experimental } \\
\left(y_{\text {ref }}\right)\end{array}$ & $\begin{array}{l}\text { Predicted } \\
\qquad\left(y_{c a l}\right)\end{array}$ & & & $\begin{array}{c}\text { Experimental } \\
\left(y_{r e f}\right)\end{array}$ & $\begin{array}{l}\text { Predicted } \\
\qquad\left(y_{c a l}\right)\end{array}$ & \\
\hline 3.31 & 459.1 & 494.30 & 7.67 & 38.21 & 653.2 & 663.65 & 1.60 & 3.5 & 377.15 & 357.45 & 5.22 \\
\hline 10.70 & 551.2 & 557.03 & 1.06 & 41.45 & 680.2 & 677.60 & 0.38 & 4.2 & 398.15 & 366.38 & 7.98 \\
\hline 19.87 & 647.2 & 620.94 & 4.06 & 42.79 & 693.2 & 683.45 & 1.41 & 5.4 & 423.15 & 380.72 & 10.03 \\
\hline 24.80 & 670.2 & 653.34 & 2.52 & 46.41 & 700.2 & 699.55 & 0.09 & 7.5 & 448.15 & 403.81 & 9.89 \\
\hline 30.83 & 693.2 & 692.51 & 0.10 & 47.36 & 706.2 & 703.86 & 0.33 & 10.9 & 493.15 & 437.88 & 11.21 \\
\hline 34.13 & 710.2 & 714.03 & 0.54 & 49.69 & 716.2 & 714.58 & 0.23 & 14.1 & 519.15 & 467.70 & 9.91 \\
\hline 31.98 & 720.2 & 699.99 & 2.81 & 52.88 & 723.2 & 718.05 & 0.71 & 14.6 & 523.15 & 472.23 & 9.73 \\
\hline 35.29 & 733.2 & 721.65 & 1.58 & 56.86 & 726.2 & 726.90 & 0.10 & 18.0 & 546.15 & 502.32 & 8.02 \\
\hline 38.54 & 748.2 & 743.16 & 0.67 & 61.75 & 733.2 & 738.48 & 0.72 & 21.0 & 566.15 & 528.16 & 6.71 \\
\hline 40.81 & 768.2 & 758.39 & 1.28 & 66.32 & 746.2 & 750.21 & 0.54 & 24.7 & 589.15 & 559.48 & 5.04 \\
\hline 42.66 & 773.2 & 770.96 & 0.29 & 70.89 & 762.2 & 763.10 & 0.12 & 27.8 & 611.15 & 585.51 & 4.20 \\
\hline 45.03 & 790.2 & 787.31 & 0.37 & 72.33 & 773.2 & 767.47 & 0.74 & 30.9 & 633.15 & 611.50 & 3.42 \\
\hline 47.38 & 801.2 & 803.83 & 0.33 & & & & & 33.9 & 653.15 & 636.76 & 2.51 \\
\hline 49.65 & 810.2 & 820.13 & 1.23 & & & & & 37.0 & 673.15 & 674.52 & 0.20 \\
\hline 51.36 & 813.2 & 832.65 & 2.39 & & & & & 39.9 & 692.15 & 687.05 & 0.74 \\
\hline 51.93 & 818.2 & 836.88 & 2.28 & & & & & 42.7 & 705.15 & 699.35 & 0.82 \\
\hline 60.59 & 818.4 & 847.91 & 3.61 & & & & & 45.5 & 711.15 & 711.89 & 0.10 \\
\hline 62.35 & 846.3 & 860.39 & 1.66 & & & & & 46.2 & 713.15 & 715.07 & 0.27 \\
\hline 65.24 & 880.0 & 881.75 & 0.20 & & & & & 49.0 & 728.15 & 727.99 & 0.02 \\
\hline 69.62 & 920.3 & 916.59 & 0.40 & & & & & 51.7 & 743.15 & 740.79 & 0.32 \\
\hline \multirow[t]{9}{*}{73.81} & 967.9 & 953.49 & 1.49 & & & & & 54.4 & 753.15 & 753.99 & 0.11 \\
\hline & & & & & & & & 56.9 & 763.15 & 766.61 & 0.45 \\
\hline & & & & & & & & 58.6 & 778.15 & 775.45 & 0.35 \\
\hline & & & & & & & & 61.5 & 788.15 & 791.07 & 0.37 \\
\hline & & & & & & & & 63.6 & 807.15 & 802.86 & 0.53 \\
\hline & & & & & & & & 65.9 & 823.15 & 816.31 & 0.83 \\
\hline & & & & & & & & 68.7 & 837.15 & 833.56 & 0.43 \\
\hline & & & & \multirow{2}{*}{\multicolumn{4}{|c|}{$A A D \%=0.79$}} & 71.3 & 839.15 & 850.59 & 1.36 \\
\hline & \multicolumn{3}{|c|}{$A A D \%=1.74$} & & & & & \multicolumn{4}{|c|}{$A A D \%=1.75$} \\
\hline
\end{tabular}

$A A D \%=(1 / m) \sum_{i=1}^{m} \frac{\left|y_{i, c a l}-y_{i, r e f}\right|}{y_{i, r e f}} \times 100$ where $m$ equals 21 for ATR-W, 12 for ATR-Y and 28 for ATR-Z.

pseudocomponents obtained using the correlation presented by Kesler and Lee (1976) and Lee and Kesler (1975), and coded with -1 for the estimation of $\omega_{a c}$. Table 14 established that the number of interpolated data used to predict the BP curve appeared to have no influence, since the variation between the balance errors was minimal when considering ten (10) and twenty one (21) data.

Thus for the system adopted using twenty one (21) interpolated points, the combination of the correlations of Kesler and Lee (1976) and Lee and Kesler (1975), coded with -1 , for the estimation of $\omega_{a c}$, and of Riazi and Daubert (1980), coded with 0 , for the prediction of $M, T_{c}, P_{c}$, represents a great choice in the estimation of the thermodynamic properties of high-boiling-point petroleum fractions, when the values for the boiling point and density of the fraction as input data are available, since the errors in mass balance were $2.73 \%$ for ATR-W, $0.71 \%$ for ATR-Y and $1.12 \%$ for ATR $-Z$, and the errors in molar balance were $8.60 \%$ for ATR-W; $2.03 \%$ for ATR-Y and $2.92 \%$ for ATR-Z. 

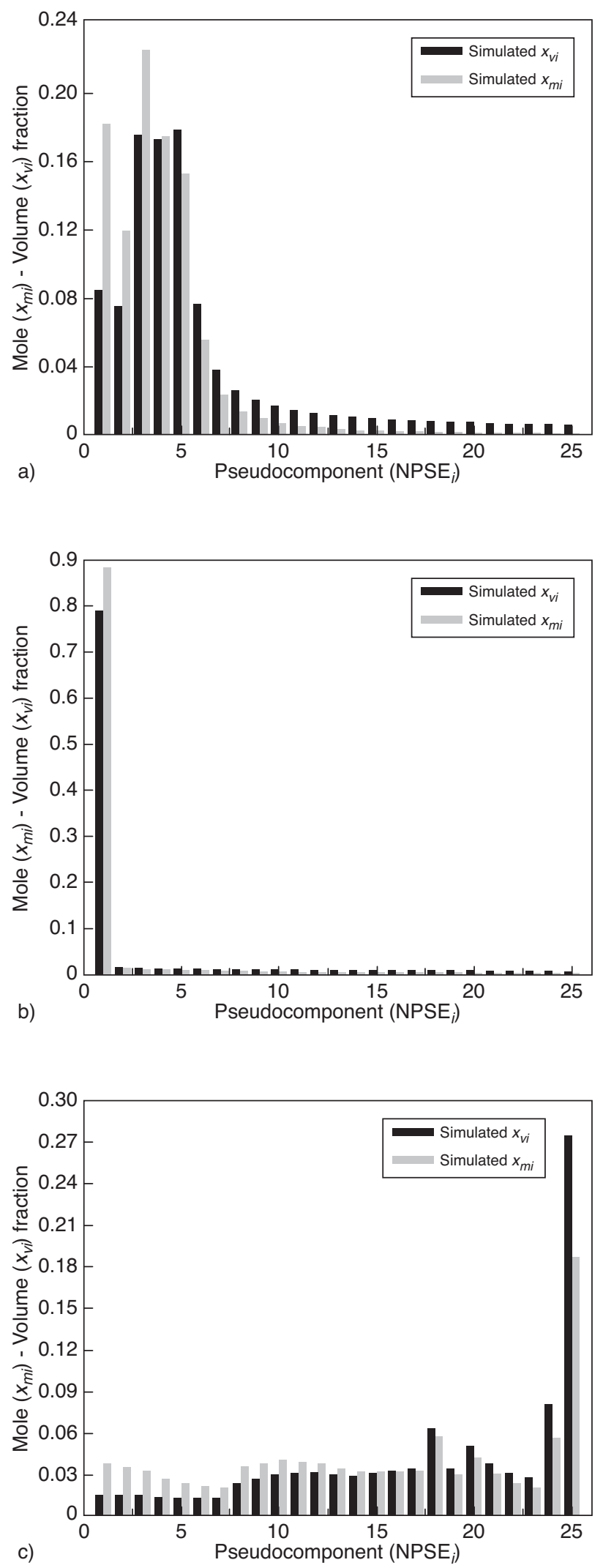

Figure 4

Pseudocomponent mol $\left(x_{m i}\right)$ - volume $\left(x_{v i}\right)$ fraction distributions of a) ATR-W; b) ATR-Y, and c) ATR-Z.
TABLE 13

Average basic and thermodynamic properties of petroleum fractions

\begin{tabular}{l|c|c|c}
\hline \multicolumn{1}{c|}{ Average basic properties } & ATR-W & ATR-Y & ATR-Z \\
\hline$C A B P(\mathrm{~K})$ & 888.8 & 783.1 & 697.1 \\
\hline$M A B P(\mathrm{~K})$ & 750.7 & 750.1 & 651.3 \\
\hline$M e A B P(\mathrm{~K})$ & 819.7 & 766.6 & 674.2 \\
\hline$K_{w}$ & 11.94 & 12.18 & 11.79 \\
\hline$\omega_{a c}$ & 1.2188 & 1.1348 & 0.8546 \\
\hline$T_{c}(\mathrm{~K})$ & 971.2 & 920.1 & 849.6 \\
\hline$P_{c}(\mathrm{MPa})$ & 0.905 & 0.962 & 1.260 \\
\hline$V_{c}\left(\mathrm{~m}^{3} \cdot \mathrm{mol}^{-1}\right)$ & $1.796 \times 10^{-3}$ & $1.636 \times 10^{-3}$ & $1.245 \times 10^{-3}$ \\
\hline
\end{tabular}

$K_{w}:$ Watson characterization factor; $C A B P$ : Cubic Average Boiling Point; $M e A B P$ : Mean Average Boiling Point; $M$ : molar mass; $P_{c}$ : critical pressure; $T_{c}$ : critical temperature; $V_{c}$ : critical volume.

Data for the Pseudocritical Properties of High-Boiling-

Point Petroleum Fractions

The critical temperature $\left(T_{c}\right)$, critical pressure $\left(P_{c}\right)$, critical volume $\left(V_{c}\right)$ and acentric factor $\left(\omega_{a c}\right)$ represent four widely used constants in physicochemical characterizations, process modeling and unit operation studies. These critical constants are very important properties in the physicochemical characterization of petroleum fractions, since almost all the thermophysical properties are estimated from the boiling point and critical constant data.

In the present work, the term pseudocritical properties were introduced to identify the effective values for the critical properties (such as temperature, pressure and volume) of the multicomponent chemical systems, ATR-W, ATR-Y and ATR-Z. Thus, the pseudocritical properties refer to the estimation of the critical properties of a set of pseudocomponents. However, the true critical properties are those calculated using the associated mixing rules.

It can be seen in Figure 6 that the pseudocritical temperature $\left(T_{c N P S E}\right)$ increased with the increase in the value for $T_{b i}$, but the pseudocritical pressure $\left(P_{C N P S E}\right)(F i g .7)$ and the density (ratio between molar mass $\left(M_{N P S E}\right)$ and critical volume $\left(V_{c N P S E}\right)$ ) decreased (Fig. 8) as the $M_{N P S E}$ and $\rho_{N P S E}$ increased.

On the other hand, $\omega_{a c}$ is a concept that was introduced by Pitzer et al. (1955) and has proved to be important in the physicochemical characterization of petroleum fractions (Shouzhi et al., 2005). The value for $\omega_{a c}$ is said to be a measure of the non-sphericity (acentricity). Values for $\omega_{a c}$ can be determined from the $T_{c}, P_{c}$ and $T_{b i}$ data. In the present work, the Edmister (Edmister, 1958) and Lee-Kesler (Kesler and Lee, 1976; Lee and Kesler, 1975) methods were evaluated, but only the Lee-Kesler approach was reported (Fig. 9). Figure 9 illustrates the dependence of $\omega_{a c}$ on $T_{b i}$ and $\rho_{i}$ for the set of twenty five (25) pseudocomponents of ATR-W, ATR-Y and ATR-Z. A nearly linear variation of this property with the increasing number of carbons can be seen, since 

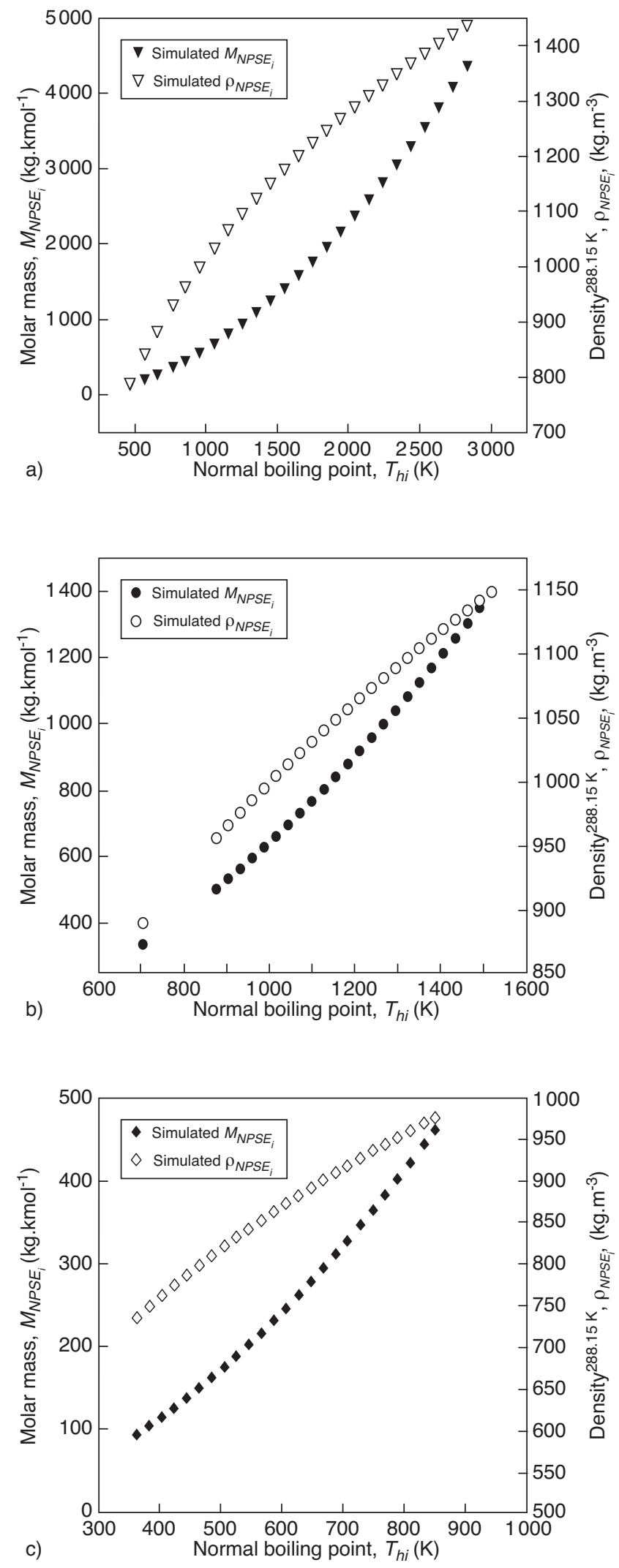

Figure 5

Density at $288.15 \mathrm{~K}\left(\rho_{N_{N S E}}{ }^{288.15 \mathrm{~K}}\right)$ and molar mass $\left(M_{N P S E_{i}}\right)$ distribution of a) ATR-W; b) ATR-Y, and c) ATR-Z. the value for $T_{b i}$ increased, and consequently the value for $\rho_{i}$ rose. Therefore, as confirmed by Ourique and Telles (1997), it is reasonable to state that the estimation of $\omega_{a c}$ must be a function of the structural and functional groups, but correlations to relate the structures and $\omega_{a c}$ are often limited to specific hydrocarbon compounds.

\subsection{Thermophysical Properties of the Whole Fractions}

Figures 10-13 present the thermophysical properties for the three Brazilian high-boiling-point petroleum fractions (ATR-W, ATR-Y and ATR-Z), calculated in a temperature range from 350 to $600 \mathrm{~K}$ according to the semi-theoretical method mentioned in Equations (21-29). Therefore, the data computed were compared with the experimental data obtained in our research laboratories.

\subsubsection{Transport Properties}

\section{Kinematic Viscosity}

The estimation of kinematic viscosity $(v)$ was carried out using two correlations $(E q .22,23)$ aiming to compare the methods with respect to the experimental data (Fig. 10, Tab. 15). Thus, the methods employed varied with the type of fraction analyzed. The comparison of these different methods showed that they produced consistent results with each other.

Several factors are responsible for the viscosity of oil and its fractions. In the specific case study approached here, the viscosity showed a general trend to decrease with increasing temperature and increase with increasing pressure and density, and it also depended on the molecular structure of the hydrocarbons. According to this, it was found that the value for $v$ increased for pseudocomponents with the high molar mass. This was because the flow was facilitated by the possibility of larger flexibility or deformation of molecules that have a smaller number of carbons in their compositions. With respect to this question, the presence of certain functional groups capable of forming hydrogen bonds leads to an increase in the intermolecular size, even resulting in an increase in $v$, such as, for example, in the ATR-Y case study, since it is rich in asphaltene chains.

Reliable correlations that are capable of estimating the value of $v$ for undefined high-boiling-point petroleum fractions (ATR-W, ATR-Y and ATR-Z), using the minimum input information, were used. Simulated data were compared with experimental data obtained in the research laboratories. The Aboul-Seoud and Moharam (1999a) correlation (Eq. 23) gives overall Average Absolute Deviation percents $(A A D \%)$ of $2.54 \%, 3.78 \%$ and $3.71 \%$ for ATR-W, ATR-Y and ATR-Z, respectively, in comparison with the method of Mehrotra (1995) (Eq. 22) that gave values of $25.64 \%, 22.52 \%$ and 27.64\%, respectively, for the Average Absolute Deviation 
TABLE 14

Mass- and molar-balance errors for assaying the reliability of thermodynamic properties considering coded acentric factor correlation ( -1$)$

\begin{tabular}{c|c|c|c|c|c|c|c|c}
\cline { 3 - 8 } & \multicolumn{2}{c}{} & \multicolumn{2}{c|}{ ATR-W } & \multicolumn{3}{c}{ ATR-Y } & \multicolumn{2}{c}{ ATR-Z } \\
\hline $\begin{array}{c}\text { Coded critical } \\
\text { property set }\end{array}$ & $\omega_{a c}$ & $\begin{array}{c}\text { Interpolated } \\
\text { data }\end{array}$ & $E_{\text {mass }}(\%)$ & $E_{\text {mol }}(\%)$ & $E_{\text {mass }}(\%)$ & $E_{\text {mol }}(\%)$ & $E_{\text {mass }}(\%)$ & $E_{\text {mol }}(\%)$ \\
\hline-1 & -1 & 21 & 1.37 & 27.45 & 0.64 & 4.86 & 1.32 & 3.99 \\
\hline-1 & -1 & 10 & 1.40 & 26.94 & 0.64 & 4.84 & 1.32 & 3.99 \\
\hline 0 & -1 & 21 & 2.73 & 8.60 & 0.71 & 2.03 & 1.12 & 2.92 \\
\hline 0 & -1 & 10 & 2.71 & 8.52 & 0.71 & 2.02 & 1.12 & 2.92 \\
\hline 1 & -1 & 21 & 3.09 & 10.08 & 0.80 & 2.33 & 1.34 & 3.36 \\
\hline 1 & -1 & 10 & 3.07 & 9.97 & 0.80 & 2.32 & 1.34 & 3.35 \\
\hline
\end{tabular}

$\omega_{a c}:$ acentric factor; $E_{\text {mass }}:$ material balance error and $E_{\text {mol }}:$ molar balance error.

percentages $(A A D \%)$. Thus, Equation (23) provides more accurate results than Equation (22) as proposed by Mehrotra (1995), since Equation (23) requires more input information and the improvement in $A A D \%$ justifies the endeavor to introduce the $S G$ as an input parameter, especially when it is readily available, together with the $M e A B P$ (for the whole fraction) and $T_{b i}$ (for the pseudocomponents), to characterize the undefined high-boiling-point petroleum fractions and its pseudocomponents.

\section{Thermal Conductivity}

Thermal conductivity $(\lambda)$ is an important property of highboiling-point petroleum fractions and it is defined from the quantity of heat transmitted due to a unit temperature gradient in a unit area under steady state conditions. It is of large importance, since heat-transfer coefficients are usually computed using correlations that require thermal conductivity data. In process engineering, a number of methods have been published for estimating the thermal conductivity of highboiling-point petroleum fractions at normal pressure. In this study, two methods have been investigated and compared with the experimental data.

Figure 11 shows the $\lambda$ plot using both the Riazi and Faghri (1985) (Eq. 24 from Tab. 5) and also Aboul-Seoud and Moharam (1999b) (Eq. 26 from Tab. 5) methods. It was showed that the second method provided better correspondence and it can be considered more accurate than the other correlations for the ATR-Y and ATR-Z fractions. In Figure 11 , a comparison was made with the data for $\lambda$ obtained for the high-boiling-point petroleum fractions by DSC experiments. Using the method of Aboul-Seoud and Moharam (1999b), values of 5.84, 5.19 and $9.01 A A D \%$, were obtained for ATR-W, ATR-Y and ATR-Z, respectively, when compared with the values of $10.73,1.39$ and $4.05 A A D \%$ for ATR-W, ATR-Y and ATR-Z obtained using the Riazi and Faghri (1985) method (Tab. 16).

\subsubsection{Thermal Properties}

Specific Heat Capacity

The specific heat capacities $\left(C_{p}\right)$ for ATR-W, ATR-Y and ATR-Z were plotted in Figure 12 for a temperature range between 350 and $600 \mathrm{~K}$. For these samples, a strong temperature dependence of the $C_{p}$ was observed in the range considered. It is apparent from Figure 12 that the $C_{p}$ of the fractions increased linearly with an increase in temperature for all the fractions. The difference in $C_{p}$ amongst the high-boilingpoint petroleum fractions was due to differences in the chemical composition. In general, the specific heat capacity might have a general effect on density and on the nature of the compounds in the mixture.

The specific heat capacities $\left(C_{p}\right)$ data were evaluated in terms of Average Absolute Deviation $(A A D \%)$ where the absolute deviation was defined as the difference between the experimental value $\left(y_{i, \text { ref }}\right)$ obtained from experimental studies and the data predicted by the computational approach $\left(y_{i, c a l}\right)$ (Tab. 16). Moreover, the results predicted were entirely consistent with those obtained experimentally in the research laboratories (LDPS/LOPCA), in which conventional Differential Scanning Calorimetrry (DSC) was employed. For ATR-W, the method of Kesler and Lee (1976) gave an overall Average Absolute Deviation $(A A D \%)$ of $2.61 \%$, as compared to $8.65 \%$ for the Watson and Nelson (1933) method; for ATR-Y the method of Kesler and Lee (1976) gave $9.72 \%$ as compared to $12.19 \%$ for the Watson and Nelson (1933) method, and for ATR-Z the method of Kesler and Lee (1976) gave $8.58 \%$ AAD as compared to $13.00 \%$ for the Watson and Nelson (1933) method (Tab. 16).

\section{Predicted Vapor Pressure}

Vapor pressure $\left(P_{\text {vap }}\right)$ predictions as a function of temperature were carried out using Equation (29). As a general trend, the relation between $P_{v a p}$ and temperature is non-linear. The $P_{v a p}$ of the samples, at a given temperature, increases as the value for $M e A B P$ increases. This is illustrated in the vapor pressure 


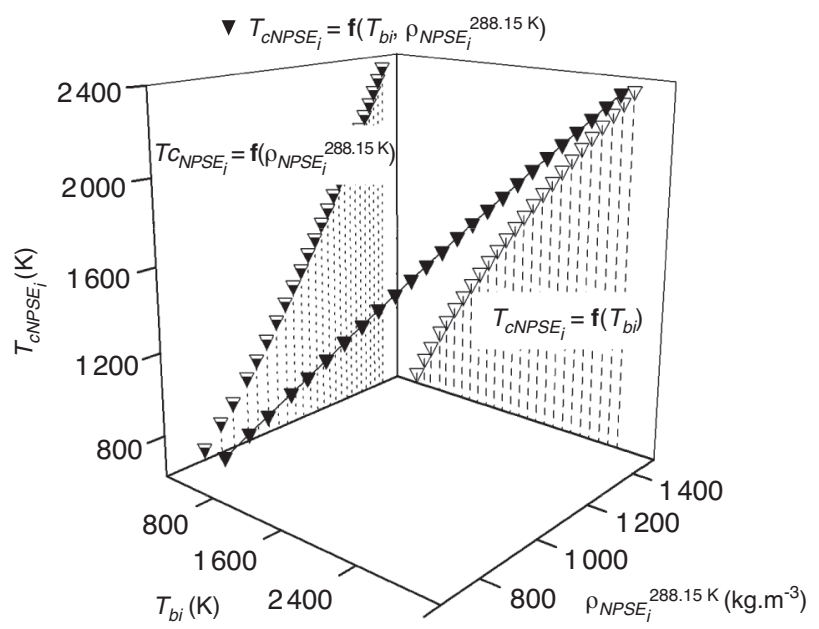

a)

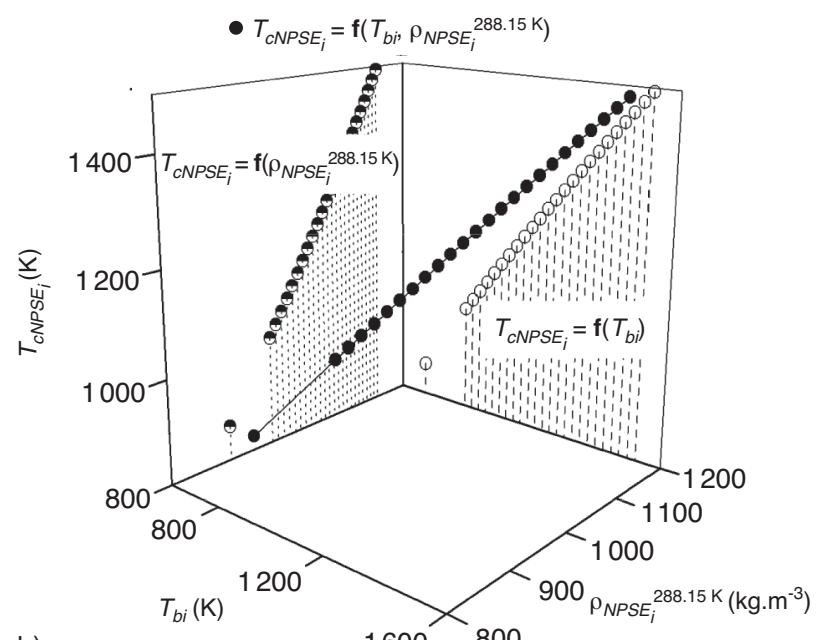

b)

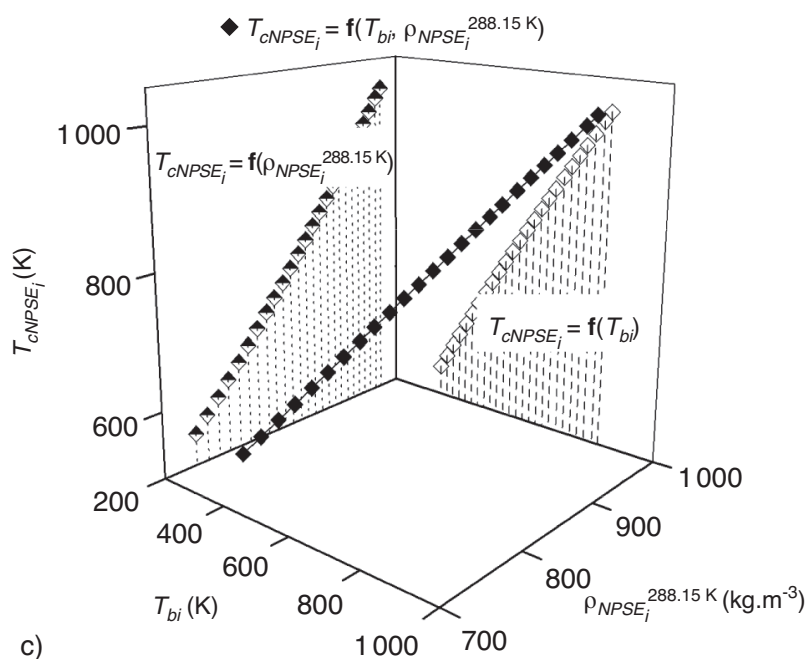

Figure 6

Pseudocritical temperature $\left(T_{c_{N P S E}}\right)$ as a function of normal boiling point $\left(T_{b i}\right)$ and density at $288.15 \mathrm{~K}\left(\rho_{N P S E_{i}}{ }^{288.15 \mathrm{~K}}\right)$ of a) ATR-W, b) ATR-Y and c) ATR-Z.

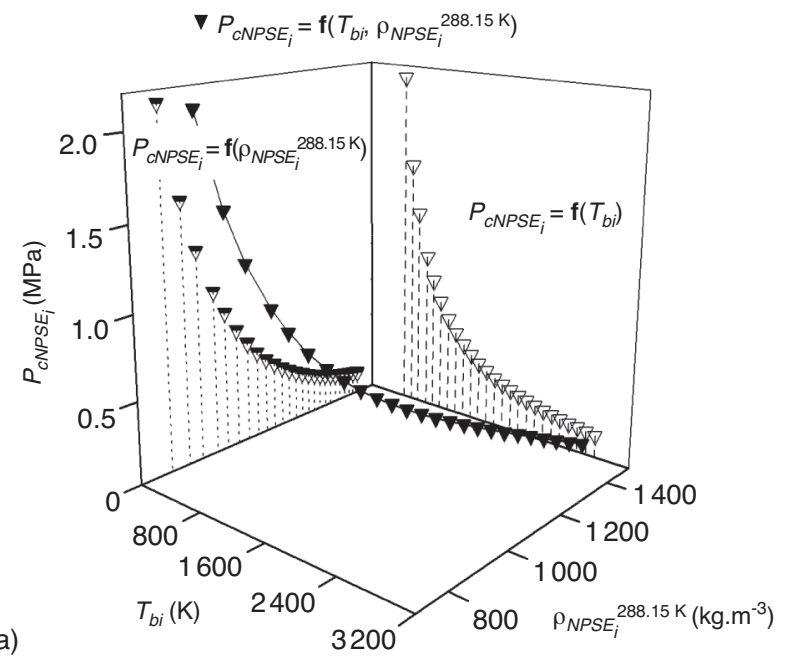

b)
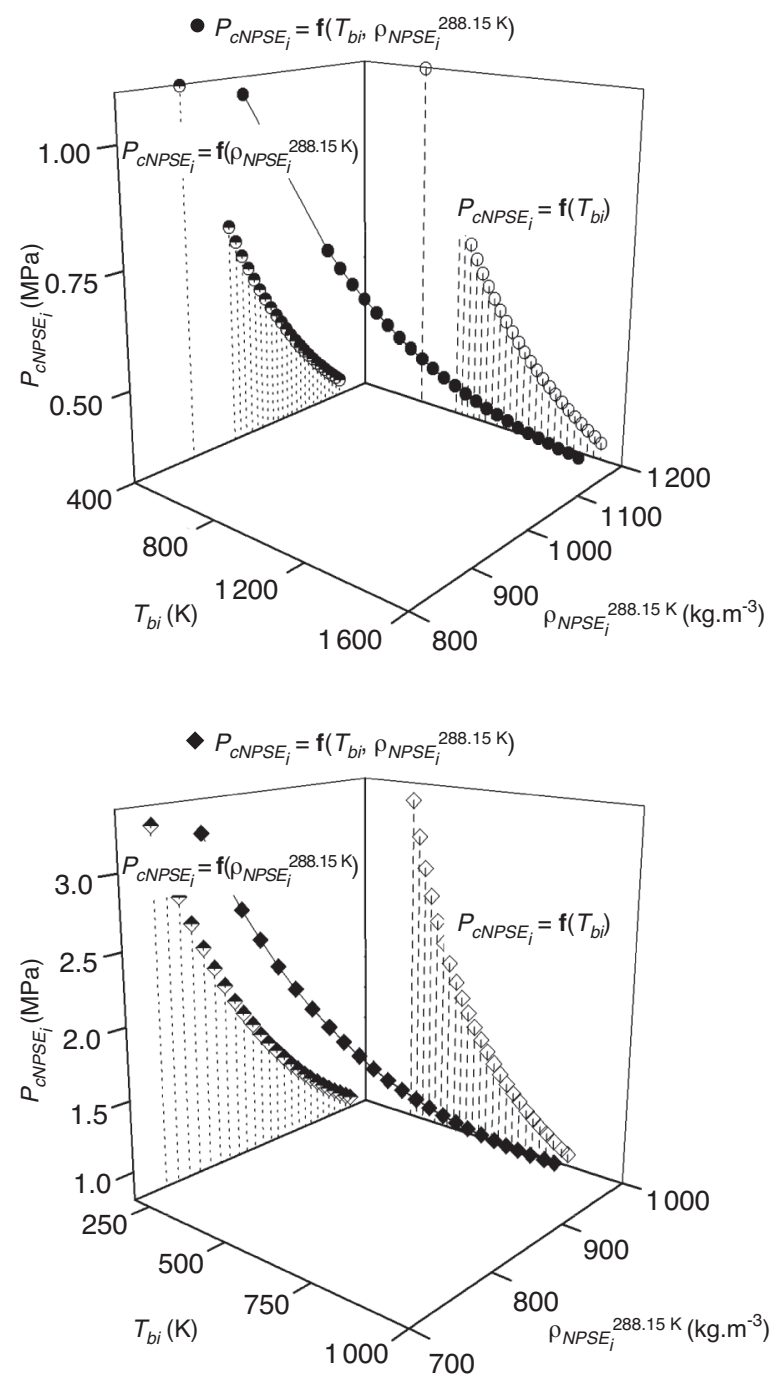

Figure 7

Pseudocritical pressure $\left(P_{c_{N P S E}}\right)$ as a function of normal boiling point $\left(T_{b i}\right)$ and density at $288.15 \mathrm{~K}\left(\rho_{N P S E_{i}}{ }^{288.15 \mathrm{~K}}\right)$ of a) ATR-W, b) ATR-Y and c) ATR-Z. 

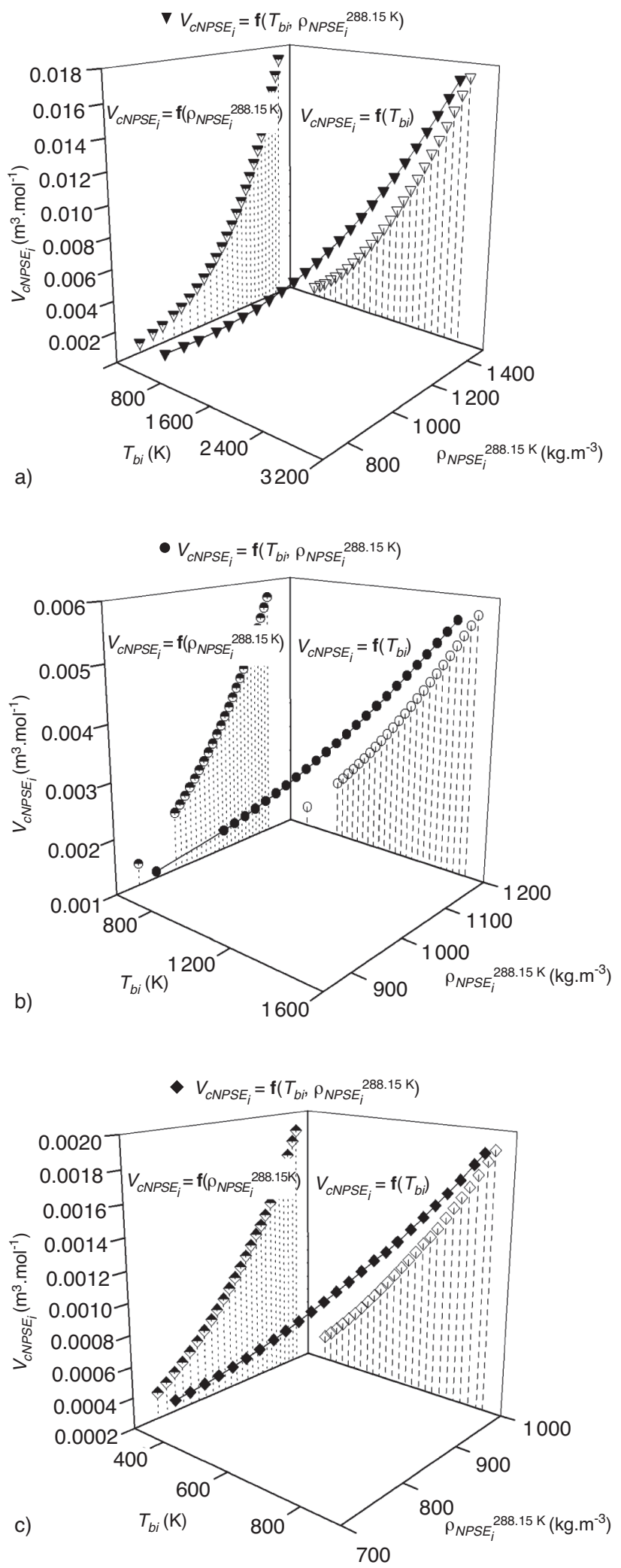

Figure 8

Pseudocritical volume $\left(V_{C_{N P S E}}\right)$ as a function of normal boiling point $\left(T_{b i}\right)$ and density at $288.15 \mathrm{~K}\left(\rho_{N P S E_{i}}{ }^{288.15 \mathrm{~K}}\right)$ of a) ATR-W, b) ATR-Y and c) ATR-Z.

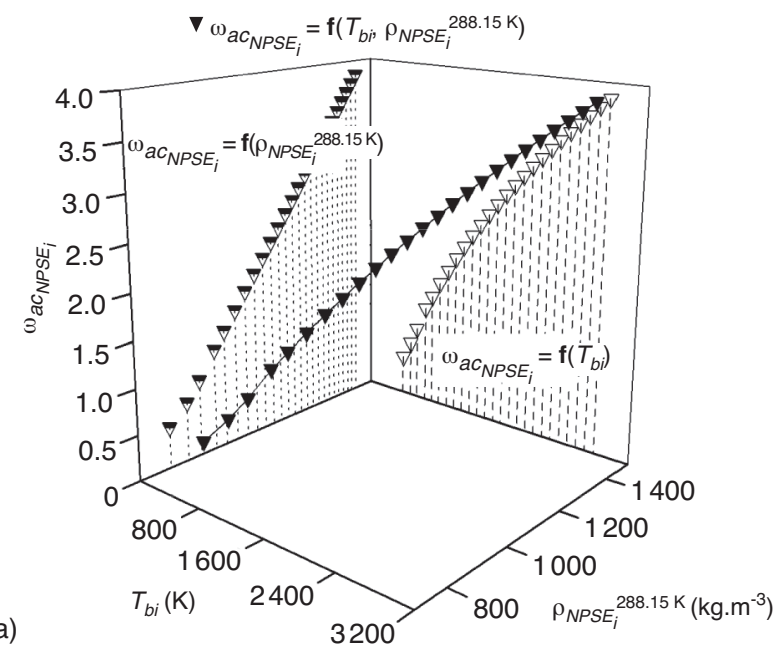

b)
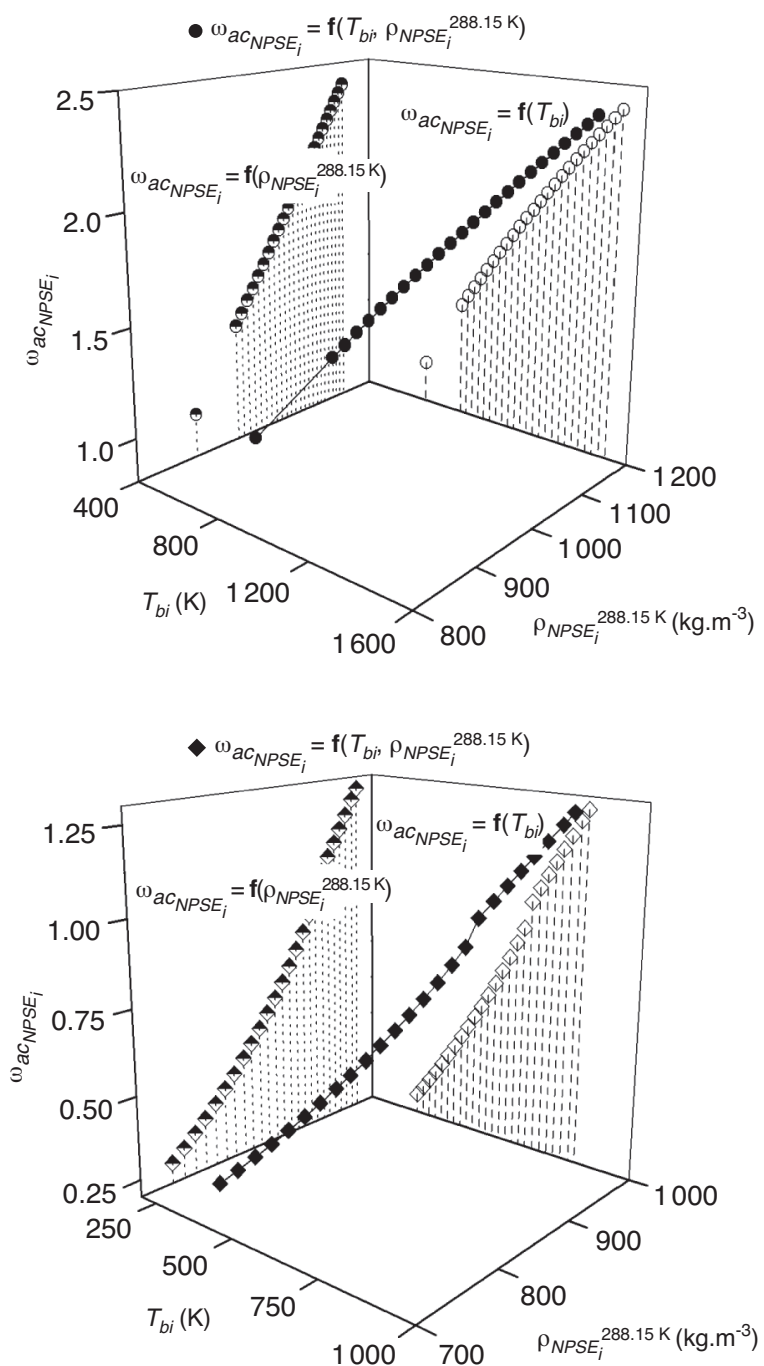

Figure 9

Pseudocritical acentric factor $\left(\omega_{a c_{N P S E}}\right)$ as a function of normal boiling point $\left(T_{b i}\right)$ and density at $288.15 \mathrm{~K}\left(\rho_{N_{P S E}}{ }^{288.15 \mathrm{~K}}\right)$ of a) ATR-W, b) ATR-Y and c) ATR-Z. 

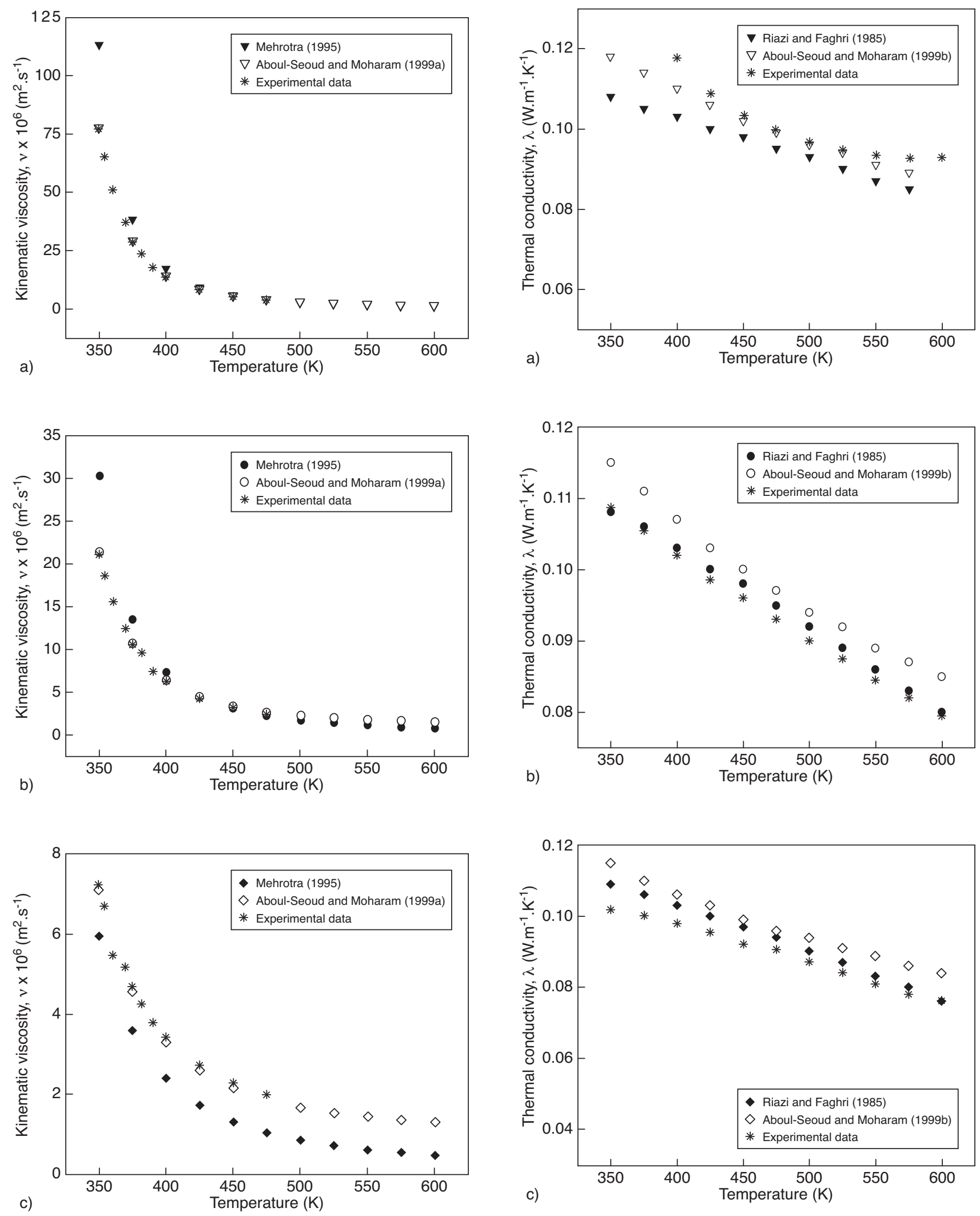

Figure 10

Kinematic viscosity $(v)$ as function of temperature $(T)$ for a) ATR-W, b) ATR-Y and c) ATR-Z and comparison with experimental data $(*)$.

Figure 11

Thermal conductivity $(\lambda)$ as function of temperature $(T)$ for a) ATR-W, b) ATR-Y and c) ATR-Z and comparison with experimental data $(*)$. 

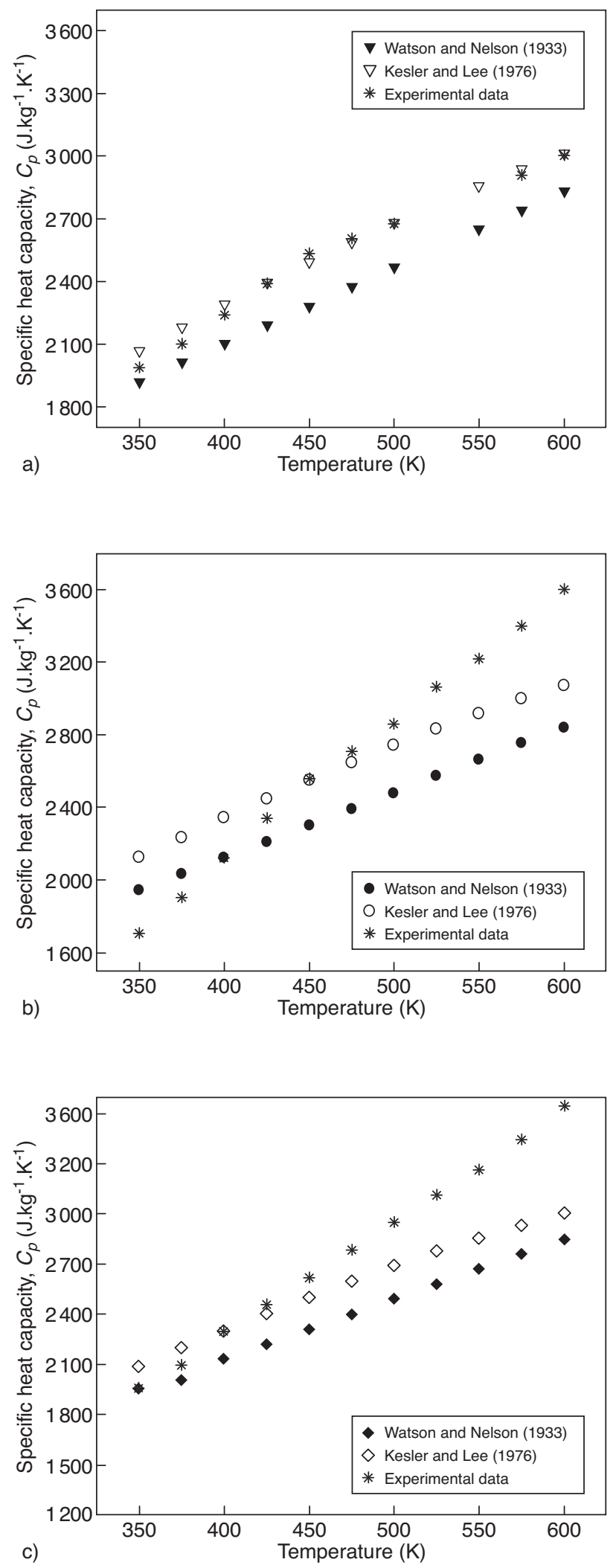

Figure 12

Specific heat capacity $\left(C_{p}\right)$ as function of temperature $(T)$ for a) ATR-W, b) ATR-Y and c) ATR-Z and comparison with experimental data $(*)$.

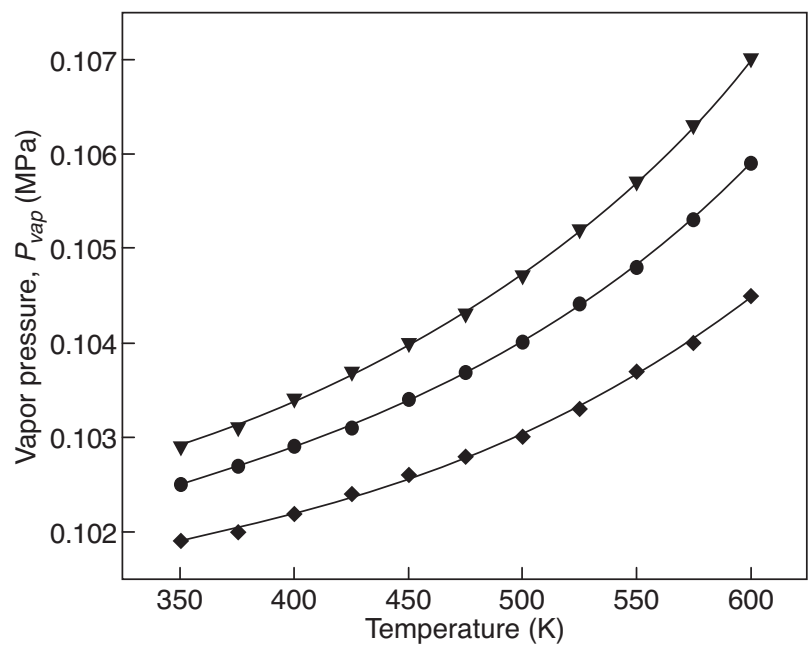

Figure 13

Vapor pressure $\left(P_{\text {vap }}\right)$ of whole fraction as a function of temperature $(T)$. ATR-W $(\boldsymbol{\nabla})$, ATR-Y $(\bullet)$ and ATR-Z $(\diamond)$.

chart that shows graphs of $P_{\text {vap }}$ versus temperature for ATR-W, ATR-Y and ATR-Z (Fig. 13). For example, at a given temperature (at $450 \mathrm{~K}$ ), the ATR-W sample showed the highest vapor pressure as compared to the other samples in the chart. It also had the highest $M e A B P$, equal to $819.7 \mathrm{~K}$.

However, the vapor pressure of a liquid increases as the temperature increases in a non-linear relation as shown in Figure 13 for ATR-W, ATR-Y and ATR-Z, respectively. As the temperature increased, the molecular kinetic energy of the molecules increased, and thus more molecules can escape from the liquid phase to the vapor phase. Accordingly, as the temperature increased, so did the $P_{\text {vap }}$.

At constant temperature and pressure, existing intermolecular forces of the substance are the determining factors of the $P_{v a p}$.

The effect of $M$ on $P_{v a p}$ is depicted in Figure 13. At a given temperature (at $400 \mathrm{~K}$ ) the vapor pressures for ATR-W, ATR-Y and ATR-Z differed due to differences in the length of their hydrocarbon chains and the type of intermolecular forces, namely London dispersion forces. This type of intermolecular force is related to the molecular size and has some connection with the molar mass $(M)$.

Nevertheless, possible non-polar pseudocomponents present in ATR-W and ATR-Y have relatively small intermolecular forces (no hydrogen bounding and/or dipole-dipole forces), and thus these samples have a relatively high $P_{\text {vap }}$ when compared with the ATR-Z fraction.

\section{CONCLUSIONS}

The computational approach has shown to be a powerful and efficient tool to predict the physicochemical properties of 
TABLE 15

Predicted kinematic viscosity and absolute deviations percent (\%) calculated by Equations (22) and (23) at various temperatures for ATR-W, ATR-Y and ATR-Z

\begin{tabular}{|c|c|c|c|c|c|c|}
\hline \multirow{3}{*}{ Feedstock } & \multirow{3}{*}{ Temperature $(\mathrm{K})$} & \multicolumn{5}{|c|}{ Kinematic viscosity, $v \times 10^{6}\left(\mathrm{~m}^{2} \cdot \mathrm{s}^{-1}\right)$} \\
\hline & & \multicolumn{2}{|c|}{ Predicted data $\left(y_{c a l}\right)$} & \multirow{2}{*}{$\begin{array}{c}\text { Experimental } \\
\text { data }\left(y_{r e f}\right)\end{array}$} & \multicolumn{2}{|c|}{ Absolute deviations percent $(\%)$} \\
\hline & & Equation (22) & Equation (23) & & Equation (22) & Equation (23) \\
\hline \multirow[t]{17}{*}{ ATR-W } & 350.0 & 113.242 & 77.898 & 77.694 & 45.754 & 0.263 \\
\hline & 354.2 & 92.150 & 64.544 & 65.454 & 40.786 & 1.390 \\
\hline & 360.6 & 68.713 & 49.411 & 51.067 & 34.555 & 3.243 \\
\hline & 369.7 & 47.041 & 35.044 & 37.011 & 27.100 & 5.315 \\
\hline & 375.0 & 38.430 & 29.199 & 28.995 & 32.540 & 0.704 \\
\hline & 381.8 & 30.181 & 23.502 & 23.444 & 28.737 & 0.247 \\
\hline & 390.3 & 22.883 & 18.358 & 17.700 & 29.282 & 3.718 \\
\hline & 400.0 & 17.193 & 14.259 & 14.055 & 22.327 & 1.451 \\
\hline & 425.0 & 9.267 & 8.360 & 8.156 & 13.622 & 2.501 \\
\hline & 450.0 & 5.682 & 5.577 & 5.373 & 5.751 & 3.797 \\
\hline & 475.0 & 3.819 & 4.084 & 3.880 & 1.572 & 5.258 \\
\hline & 500.0 & 2.746 & 3.202 & - & - & - \\
\hline & 525.0 & 2.077 & 2.642 & - & - & - \\
\hline & 550.0 & 1.634 & 2.266 & - & - & - \\
\hline & 575.0 & 1.327 & 2.002 & - & - & - \\
\hline & 600.0 & 1.105 & 1.809 & - & - & - \\
\hline & & & & & $A A D \%=25.64$ & $A A D \%=2.54$ \\
\hline \multirow[t]{17}{*}{ ATR-Y } & 350.0 & 30.230 & 21.297 & 21.063 & 43.522 & 1.111 \\
\hline & 354.2 & 25.953 & 18.663 & 18.602 & 39.517 & 0.328 \\
\hline & 360.6 & 20.870 & 15.470 & 15.589 & 33.876 & 0.763 \\
\hline & 369.7 & 15.727 & 12.154 & 12.423 & 26.596 & 2.165 \\
\hline & 375.0 & 13.512 & 10.692 & 10.457 & 29.215 & 2.247 \\
\hline & 381.8 & 11.260 & 9.180 & 9.6333 & 16.886 & 4.706 \\
\hline & 390.3 & 9.125 & 7.718 & 7.4334 & 22.757 & 3.829 \\
\hline & 400.0 & 7.332 & 6.463 & 6.229 & 17.707 & 3.757 \\
\hline & 425.0 & 4.537 & 4.442 & 4.208 & 7.818 & 5.561 \\
\hline & 450.0 & 3.079 & 3.343 & 3.109 & 0.965 & 7.527 \\
\hline & 475.0 & 2.233 & 2.686 & 2.451 & 8.894 & 9.588 \\
\hline & 500.0 & 1.704 & 2.264 & - & - & - \\
\hline & 525.0 & 1.352 & 1.978 & - & - & - \\
\hline & 550.0 & 1.106 & 1.776 & - & - & - \\
\hline & 575.0 & 0.929 & 1.628 & - & - & - \\
\hline & 600.0 & 0.796 & 1.516 & - & - & - \\
\hline & & & & & $A A D \%=22.52$ & $A A D \%=3.78$ \\
\hline \multirow[t]{17}{*}{ ATR-Z } & 350.0 & 5.953 & 7.105 & 7.226 & 17.617 & 1.675 \\
\hline & 354.2 & 5.419 & 6.528 & 6.688 & 18.974 & 2.392 \\
\hline & 360.6 & 4.731 & 5.788 & 5.466 & 13.447 & 5.891 \\
\hline & 369.7 & 3.957 & 4.959 & 5.170 & 23.462 & 4.081 \\
\hline & 375.0 & 3.592 & 4.568 & 4.689 & 23.395 & 2.581 \\
\hline & 381.8 & 3.193 & 4.142 & 4.255 & 24.959 & 2.656 \\
\hline & 390.3 & 2.783 & 3.707 & 3.791 & 26.589 & 2.216 \\
\hline & 400.0 & 2.407 & 3.308 & 3.429 & 29.805 & 3.529 \\
\hline & 425.0 & 1.738 & 2.601 & 2.722 & 36.150 & 4.445 \\
\hline & 450.0 & 1.325 & 2.168 & 2.289 & 42.114 & 5.286 \\
\hline & 475.0 & 1.053 & 1.884 & 2.005 & 47.481 & 6.035 \\
\hline & 500.0 & 0.866 & 1.689 & - & - & - \\
\hline & 525.0 & 0.731 & 1.549 & - & - & - \\
\hline & 550.0 & 0.631 & 1.445 & - & - & - \\
\hline & 575.0 & 0.556 & 1.367 & - & - & - \\
\hline & 600.0 & 0.497 & 1.306 & - & - & - \\
\hline & & & & & $A A D \%=27.64$ & $A A D \%=3.71$ \\
\hline
\end{tabular}

$A A D \%=(1 / m) \sum_{i=1}^{m} \frac{\left|y_{i, c a l}-y_{i, r e f}\right|}{y_{i, r e f}} \times 100$ where $m$ equals 11. 
TABLE 16

Predicted thermal conductivity specific heat capacity and absolute deviations percent $(\%)$ calculated by Equations $(24,26)$ and $(27,28)$, respectively, at various temperatures for ATR-W, ATR-Y and ATR-Z

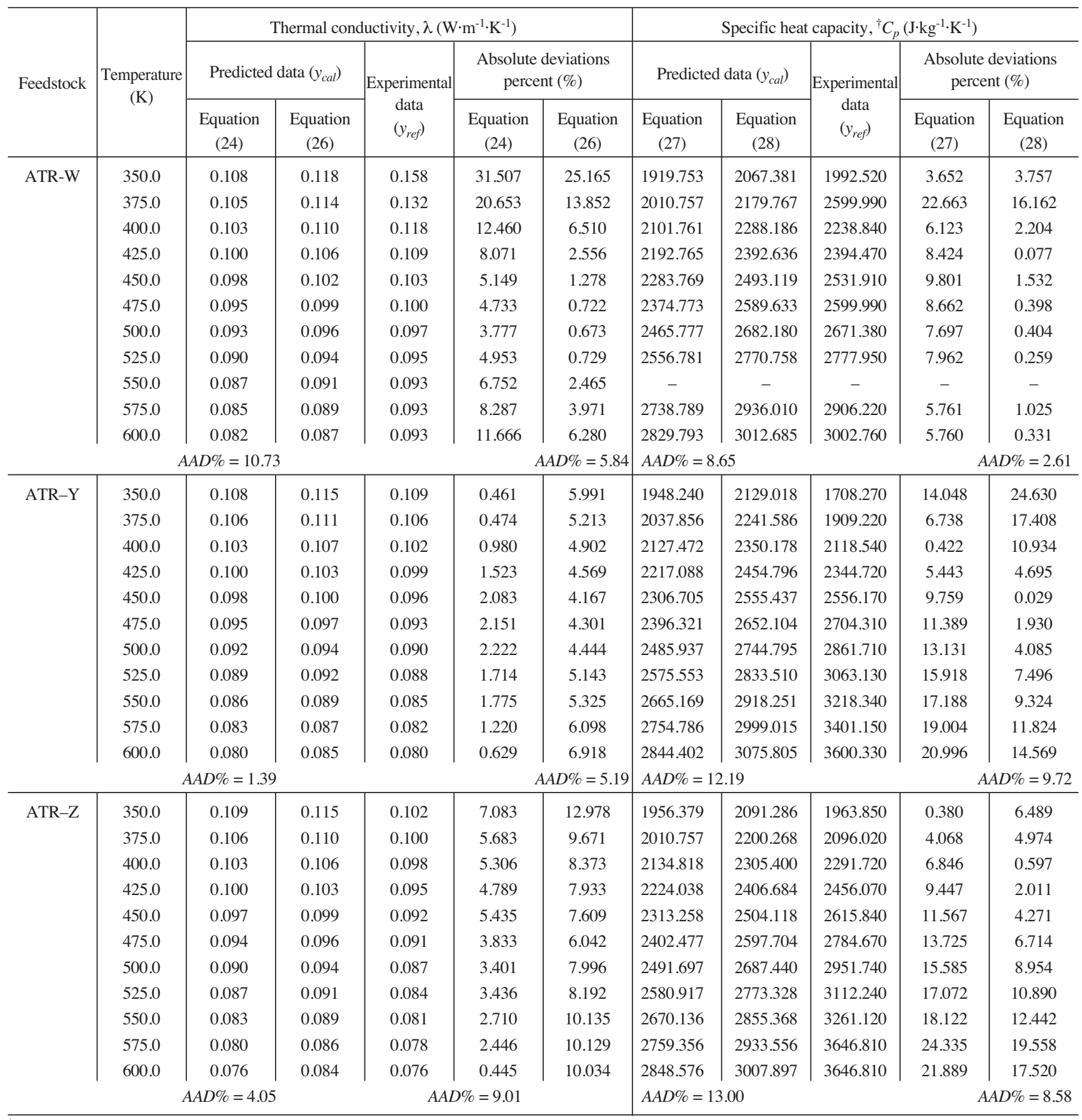

$A A D \%=(1 / m) \sum_{i=1}^{m} \frac{\left|y_{i, c a l}-y_{i, r e f}\right|}{y_{i, r e f}} \times 100$ where $m$ equals $11 . \dagger m$ equals 10 to compute $A A D \%$ by Equations $(27,28)$ in order to estimate specific heat capacity for ATR-W.

petroleum fractions. The method requires a boiling point curve and the specific gravity as the input data information. This method focuses specifically on high-boiling-point petroleum fractions and the selection of the right characterization method has an important effect on the properties calculated.
Moreover, the computational procedure can be combined with or incorporated into petroleum process simulations or assist studies about petroleum processing by providing an easy and accurate method for characterization of petroleum fraction properties with lower computational effort. 
The critical properties were assayed by way of an optimization exercise to obtain the best set of correlations for estimating the molar mass $(M)$, critical properties $\left(T_{c}, P_{c}\right)$ and acentric factor $\left(\omega_{a c}\right)$. Accordingly, a set established by Equations (12-14) (coded by 0) and Equation (19) (coded by -1) comprised the correlations with which it was possible to obtain the lowest mass and molar balance errors.

The critical properties such as critical temperature $\left(T_{c}\right)$ and critical pressure $\left(P_{c}\right)$ were sensitive to the normal boiling point $\left(T_{b i}\right)$ and density $\left(\rho_{i}\right)$ of the pseudocomponents. For higher values of $T_{b i}$, the value for $T_{c N P S E}$ increased, but the value for $P_{C N P S E}$ and the ratio between $M_{N P S E}$ and $V_{c N P S E}$ decreased. This result reflects the relationship between the thermodynamic properties and the amount of hydrocarbons and type of chains amongst them.

A set of reliable correlations can be used to estimate the thermophysical and transport properties with a minimal number of input data such as the MeABP (Mean Average Boiling Point), in the case of a whole petroleum fraction or $T_{b i}$ (normal boiling point) for each pseudocomponent, together the $S G$ (Specific Gravity). The proposed method seems to be simple and flexible. The data computed were in good agreement with the experimental data obtained in the research laboratories, since the $A D D \%$ was lower than $10 \%$. Hence, the model of Aboul-Seoud and Moharam (1999b) for the prediction of the thermal conductivity $(\lambda)$ of high-boiling-point petroleum fractions, which requires as input information the value of $T_{b}$, was evaluated in this work and compared with that of Riazi and Faghri (1985). The model of Aboul-Seoud and Moharam (1999b) provided satisfactory results, which were much better than those obtained with the second model since good agreement between the predicted and experimental values has been found, with an overall absolute deviation of 5.84, 5.19 and $9.01 \%$ for ATR-W, ATR-Y and ATR-Z, respectively.

Aboul-Seoud and Moharam (1999a) method, Equation (23), showed the lowest standard deviation (below 5\%) for predicting the kinematic viscosity $(v)$ values of the analyzed high-boiling-point petroleum fractions in the Newtonian range from 350 to $600 \mathrm{~K}$, when compared with the Mehrotra (1995) method (Eq. 22).

The results obtained for the specific heat capacity $\left(C_{p}\right)$ for the selected high-boiling-point petroleum fractions (ATR-W, ATR-Y and ATR-Z) provided reliable data using the correlation proposed by Kesler and Lee (1976), since the values for the $A A D \%$ were $2.61 \%, 9.72 \%$ and $8.58 \%$ for ATR-W, ATR-Y and ATR-Z, respectively.

In this work, a simple correlation was used for the estimation of the vapor pressure $\left(P_{\text {vap }}\right)$ of the high-boilingpoint petroleum fractions, where only the boiling point $\left(T_{b}\right)$ and the temperature $(T)$ are required.

\section{ACKNOWLEDGMENTS}

This research was supported by the Brazilian National Council for Technological and Scientific Development $(\mathrm{CNPq})$, the Petrobras Research and Development Center (PETROBRAS/CENPES) and the Brazilian Study and Project Financing Institution (FINEP).

\section{REFERENCES}

Aboul-Seoud A.-L., Moharam H.M. (1999a) Short communication - A generalized viscosity correlation for undefined petroleum fractions, Chem. Eng. J.72, 3, 253-256.

Aboul-Seoud A.-L., Moharam H.M. (1999b) A simple thermal conductivity-temperature correlation for undefined petroleum and coal liquid fractions, Chem. Eng. Res. Des. 77, 3, 248-252.

American Society for Testing Materials, ASTM D 287: Standard test method for API gravity of crude petroleum and petroleum products (Hydrometer method). West Conshohoken, (Pennsylvania): ASTM International, 1992, 3 p., [Reapproved 2006].

American Society for Testing Materials, ASTM D 1298. Standard test method for density, relative density (specific gravity), or API gravity of crude petroleum and liquid petroleum products by hydrometer method. West Conshohoken, (Pennsylvania): ASTM International, 1999, 6 p., [Reapproved 2005].

American Society for Testing Material, ASTM D 2892. Standard test method for distillation of crude petroleum (15-Theoretical plate column). West Conshohoken, (Pennsylvania): ASTM International, 2005, 32 p.

Beer E. (1994) Petroleum fractions characterization and breakdown into pseudocomponents, Nafta 45, 12, 617-627.

Boozarjomehry R.B., Abdolahi F., Moosavian M.A. (2005) Characterization of basic properties for pure substances and petroleum fractions by neural network, Fluid Phase Equilibr. 231, 2, 188-196.

Coats K.H. (1985) Simulation of gas condensate reservoir performance, J. Petrol. Technol.37, 10, 1870-1886.

Danesh A. (1998) PVT and phase behavior of reservoir fluids, in Developments in Petroleum Science, Elsevier Science, New York.

Daubert T.E., Danner R.P., Sibul H.M., Stebbins C.C., Oscarson J.L., Zundel N., Marshal T.L., Adams M.E., Wilding W.V. (2000) Physical and Thermodynamic Properties of Pure Chemicals: DIPPR: Data Compilation, 10th ed., Taylor and Francis.

Daubert T.E., Danner R.P. (1997) API Tecnhnical Data book-petroleum refining, 6th ed., American Petroleum Institute (API), Washington, D.C.

Eckert E., Vaněk T. (2005) New approach to the characterisation of petroleum mixtures used in the modelling of separation processes, Comput. Chem. Eng. 30, 2, 343-356.

Edmister W.C. (1958) Applied hydrocarbon thermodynamics, Part 4: Compressibility factors and equations of state, Petroleum Refiner 37, 4, 173-179.

Gharagheizi F., Fazeli A. (2008) Prediction of the Watson characterization factor of hydrocarbon components from molecular properties, QSAR Comb. Sci. 27, 6, 758-767.

Hu S., Zhu F.X.X. (2001) A general framework for incorporating molecular modelling into overall refinery optimisation, Appl. Therm. Eng. 21, 13-14, 1331-1348.

Kesler M.G., Lee B.I. (1976) Improve Prediction of enthalpy of fractions, Hydrocarbon Processing 55, 3, 153-158. 
Korsten H. (1998) Critical properties of hydrocarbon systems, Chem. Eng. Technol. 21, 3, 229-244.

Lakshmi D.S., Prasad D.H.L. (1992) A rapid estimation method for thermal conductivity of pure liquids, Chem. Eng. J. 48, 3, 211-214.

Lee B.I., Kesler M.G. (1975) A generalized thermodynamic correlation based on three-parameter corresponding states, AIChE J. 21, 3, 510-527.

Lion A.R., Edmister W.C. (1975) Make equilibrium calculations by computer, Hydrocarbon Processing 54, 8, 119-122.

Mehrotra A.K. (1995) A simple equation for predicting the viscosity of crude oil fractions, Chem. Eng. Res. Des. 73, 1, 87-90.

Mehrotra A.K., Monnery W.D., Svrcek W.Y. (1996) A review of practical calculation methods for the viscosity of liquid hydrocarbons and their mixtures, Fluid Phase Equilib. 117, 1-2, 344-355.

Merdrignac I., Espinat D. (2007) Physicochemical characterization of petroleum fractions: The state of the art, Oil Gas Sci. Technol.62, $1,7-32$.

Miquel J., Castells F. (1993) Easy characterization of petroleum fractions (part 1), Hydrocarbon Processing 72, 12, 101-105.

Miquel J., Castells F. (1994) Easy characterization of petroleum fractions (part 2), Hydrocarbon Processing 73, 1, 99-109.

Moharam H.M., Al-Mehaideb R.A., Fahim M.A. (1995) New correlation for predicting the viscosity of heavy petroleum fractions, Fuel 74, 12, 1776-1779.

Nichita D.V., Pauly J., Montel F., Daridon J.-L. (2008) Pseudocomponent delumping for multiphase system with waxy solid phase precipitation, Energ. Fuel. 22, 2,775-783.

Ourique J.E., Telles A.S. (1997) Estimation of properties of pure organic substances with group and pair contributions, Brazilian J. Chem. Eng. 14, 2, 1-17.

Panteli E., Voutsas E., Magoulas K., Tassios D. (2006) Prediction of vapor pressures and enthalpies of vaporization of organic compounds from the normal boiling point temperature, Fluid Phase Equilib. 248, 1, 70-77.

Pasquini C., Bueno A.F. (2007) Characterization of petroleum using near-infrared spectroscopy: Quantitative modeling for the true boiling point curve and specif gravity, Fuel 86, 12-13, 1927-1934.

Pitzer K.S., Lippmann D.Z., Curl Jr R.F., Huggins C.M., Petersen D.E. (1955) The Volumetric and thermodynamic properties of fluids. II. Compressibility factor, vapor pressure and entropy of vaporization, J. Am. Chem. Soc. 77, 13, 3433-3440.
Poling B.E., Prausnitz J.M., O’Connel J.P. (2001) The Properties of Gases and Liquids, 5th ed., McGraw-Hill, New York.

Quann R.J., Jaffe S.B. (1992) Structure-oriented lumping: Describing the chemistry of complex hydrocarbon mixtures, Ind. Eng. Chem. Res. 31, 11, 2483-2497.

Riazi M.R. (2004) Characterization and properties of petroleum fractions, ASTM International Standards Worldwide, Kuwait.

Riazi M.R., Al-Sahhaf T.A. (1996) Physical properties of heavy petroleum fractions and crude oils, Fluid Phase Equilib. 117, 1-2, 217-224.

Riazi M.R., Daubert T.E. (1980) Simplify property predictions, Hydrocarbon Processing 59, 3, 115-116.

Riazi M.R., Faghri A. (1985) Thermal conductivity of liquid and vapor hydrocarbon system: Pentanes and heavier at low pressures, Ind. Eng. Chem. Process Des. Dev. 24, 2, 398-401.

Satyro M.A., Yarranton H. (2009) Oil Characterization from simulation of experimental distillation data, Energ. Fuel. 23, 8, 39603970.

Schlijper A.G. (1986) Simulation of compositional processes: The use of pseudocomponents in equation-of-state calculations, SPE Reserv. Eng. 1, 5, 441-452.

Shouzhi Y., Yuanyuan J., Peisheng M. (2005) Estimation of acentric factor of organic compounds with corresponding states group contribution method, Chinese J. Chem. Eng. 13, 5, 709-712.

Watson K.M., Nelson E.F. (1933) Improved methods for approximating critical and thermal properties of petroleum fractions, Ind. Eng. Chem. 25, 8, 880-887.

Watson K.M., Nelson E.F., Murphy G.B. (1935) Characterization of petroleum fractions, Ind. Eng. Chem. 27, 12, 1460-1464.

Whitson C.H., Brulé M.R. (2000) Phase Behavior. SPE Monograph series, Richardson: Society of Petroleum Engineers, Inc., Texas

Winn W. (1955) Physical properties by nomogram, Petroleum Refiner 36, 2, 157-159.

Final manuscript received in June 2011 Published online in May 2012 